AUBRY, K. B., STATHAM, M. J., SACKS, B. N., PERRINE, J. D. and WISELY, S. M. (2009), Phylogeography of the North American red fox: vicariance in Pleistocene forest refugia. Molecular Ecology, 18: 2668-2686. doi: 10.1111/j.1365-294X.2009.04222.x

\title{
Phylogeography of the North American red fox: vicariance in Pleistocene forest refugia
}

\author{
KEITH B. AUBRY, MARK J. STATHAM, BENJAMIN N. SACKS, JOHN D. \\ PERRINE and SAMANTHA M. WISELY
}

\section{Abstract}

Fossil, archaeological, and morphometric data suggest that indigenous red foxes in North America were derived from vicariance in two disjunct refugia during the last glaciation: one in Beringia and one in the contiguous USA. To test this hypothesis, we conducted a phylogeographical analysis of the North American red fox within its presettlement range. We sequenced portions of the mitochondrial cytochrome $b$ (354 bp) gene and D-loop (342 bp) from 220 historical red fox specimens. Phylogenetic analysis of the cytochrome $b$ gene produced two clades that diverged c. 400000 years before present (BP): a Holarctic and a Nearctic clade. Dloop analyses of the Nearctic clade indicated three distinct subclades $(\geq 99 \%$ Bayesian posterior probability); two that were more recently derived (rho estimate c. $20000 \mathrm{BP}$ ) and were restricted to the southwestern mountains and the eastern portion of North America, and one that was older (rho estimate c. $45000 \mathrm{BP}$ ) and more widespread in North America. Populations that migrated north from the southern refugium following deglaciation were derived from the colonization of North America during or prior to the Illinoian glaciation (300 000-130 000 BP), whereas populations that migrated south from the northern refugium represent a more recent colonization event during the Wisconsin glaciation (100 000-10 000 BP). Our findings indicate that Nearctic clade red foxes are phylogenetically distinct from their Holarctic counterparts, and reflect long-term isolation in two disjunct forest refugia during the Pleistocene. The montane 
lineage, which includes endangered populations, may be ecologically and evolutionarily distinct.

Introduction

The red fox (Vulpes vulpes) is the most widely distributed terrestrial carnivore in the world, occurring throughout most of North America, Europe, Asia, and north Africa in habitat conditions ranging from arctic tundra to temperate deserts (Lariviére \& Pasitschniak-Arts 1996). Although North American red foxes currently occupy a similarly broad range of habitats, prior to European settlement of the eastern USA, indigenous populations of the red fox were restricted primarily to the boreal forests of Canada and Alaska (V.v. alascensis, V.v. abietorum, V.v. regalis, and V.v. rubricosa), and the subalpine parklands and alpine meadows of the Rocky Mountains (V.v. macroura), Cascade Range (V.v. cascadensis), and Sierra Nevada (V.v. necator) in the western contiguous USA (hereafter, the montane red foxes; Seton 1929; Churcher 1959; Aubry 1983; Kamler \& Ballard 2002). Historical and archaeological evidence suggests that populations of red foxes that currently occupy low-elevation habitats in the contiguous USA originated from range expansions into habitats altered by human activities, intentional translocations, or escapes from fur farms (Gilmore 1946; Churcher 1959; Guilday et al. 1978; Aubry 1984; Lewis et al. 1999; Kamler \& Ballard 2002; but see Perrine et al. 2007). Thus, the presettlement distribution of indigenous red foxes in North America was primarily boreo-montane in nature.

The fossil record indicates that the red fox initially colonized North America from Eurasia across the Bering Land Bridge during the Illinoian glaciation [c. 300 000- 130000 years before present (BP); Péwé \& Hopkins 1967], then expanded southward into the contiguous USA during the Sangamon interglacial (c. 130 000-100 000 BP; Pinsof et al. 1996). During the Wisconsin glaciation (c. 100 000- 10000 BP), North American red foxes were isolated in two disjunct refugia (Péwé 
1975; Harington 1977; Faunmap Working Group 1994): unglaciated portions of Alaska and the Yukon (Beringia) that were then connected by land to Asia (hereafter, the northern refugium) and the unglaciated areas south of the ice sheets in the contiguous USA (hereafter, the southern refugium).

Morphometric data from several Wisconsin-age adult fossil skulls suggests that northern refugial red foxes may have been substantially larger than those in the southern refugium. A Wisconsin-age specimen from the Old Crow River in the Yukon had a condylobasal length (CBL) of $150 \mathrm{~mm}$ (Harington 1977), whereas three Wisconsin-age crania from southeastern Wyoming had an estimated mean ( \pm SD) CBL of $126.8 \pm 7.3$ mm [Anderson 1968; A. Roest (deceased), California Polytechnic State University, unpublished data]. The cranium from the northern refugium was larger than most modern specimens from that region, whereas the crania from the southern refugium were about $5 \mathrm{~mm}$ smaller than modern specimens from the southern Rocky Mountains (Anderson 1968; Harington 1977). Variation in skull size among modern populations of the red fox in boreal regions provides additional support for vicariance in glacial refugia. Although Churcher (1959) reported an approximately continuous cline in morphological variation among red foxes from Eurasia across the Bering Strait to Alaska and southeastern Canada, the montane red foxes were not part of this northern cline. Near the southern borders of British Columbia and Alberta, the relatively large western Canadian red foxes [mean CBL $=143.7 \pm 5.7 \mathrm{~mm}$ for adult males $(n=19)$ and $135.8 \pm 4.0$ for adult females $(n=27)]$ occur in close proximity to populations restricted to high-elevation habitats in the Cascade Range and Rocky Mountains. However, in addition to having unique habitat affinities (Aubry 1983; Kamler \& Ballard 2002), the montane red foxes [mean CBL $=136.5 \pm 4.2 \mathrm{~mm}$ for adult males $(n=37)$ and $132.8 \pm 4.3$ for adult females $(n=39)$ ] are significantly smaller than those occurring in Western Canada ( $t=-5.39, P \leq 0.001$ and $t=-2.90, P \leq 0.01$ for males and females, respectively) [A. Roest (deceased), California Polytechnic State University and K. Aubry, US Forest 
Service, unpublished data]. Thus, there is an abrupt discontinuity in skull size among indigenous populations of red foxes in the Pacific Northwest, suggesting that the red fox may exhibit the same phylogeographical discontinuity found in other boreal mammals that delineates a zone of secondary contact after vicariance in Pleistocene forest refugia (Arbogast \& Kenagy 2001).

Macpherson (1965) speculated that modern populations of the red fox in Alaska and Canada were derived solely from northward range expansion by southern refugial populations after glacial retreat (hereafter, the one-refugium hypothesis), but the discovery of Wisconsin-age fossils of the red fox in Beringia (Péwé 1975; Harington 1977) cast doubt on that scenario. Based on analyses of ecological, historical, archaeological, fossil, and morphometric data, Aubry (1983) hypothesized that the Quaternary zoogeography of the red fox in North America was more complicated, and reflected vicariance in southern and northern forest refugia during the Wisconsin glaciation, and secondary contact during the Holocene (hereafter, the two-refugia hypothesis). Aubry proposed that as the ice sheets retreated and rising sea level re-established the Bering Strait, red foxes in the northern refugium became separated from Eurasian populations. When portions of Alaska and Canada were revegetated as the Wisconsin glaciers retreated eastward from Alaska and northward from southern regions, red foxes in the northern refugium expanded their range southeastward across Canada. As boreal forests migrated north in the eastern USA during glacial retreat, red foxes in that portion of the southern refugium either migrated north into eastern and central Canada, or were extirpated. However, in montane regions of the western USA, red foxes and other species associated with the boreal forest biome shifted their ranges both latitudinally and elevationally as climatic conditions warmed and suitable habitat conditions moved upward in elevation and contracted in geographical extent (Guralnick 2007). Here, we use genetic analyses to test these hypotheses. 
Genetic data have been used to investigate elevational isolation of red foxes in Yellowstone National Park (Swanson et al. 2005), and the persistence of indigenous red foxes in the mountains of California (Perrine et al. 2007), but no phylogeographical analyses have been conducted on North American red foxes. Understanding the Pleistocene phylogeography of organisms associated with the boreal forest biome will help researchers predict the potential effects of future climate change on their distributions, and delineate appropriate units for conservation and management. Our objectives were to conduct a phylogeographical analysis of indigenous populations of the red fox in North America using mitochondrial DNA to determine whether: (i) genetic patterns and divergence times support the tworefugia hypothesis, (ii) the observed morphometric discontinuity among red foxes in the Pacific Northwest reflects a phylogeographical discontinuity that corresponds to those reported for other boreal mammals, (iii) the morphometric cline from Alaska through southeastern Canada resulted from isolation by distance within a single lineage, or from secondary contact and incomplete mixing of two or more distinct lineages, and (iv) to provide an empirical framework for evaluating the genetic affinities and conservation status of extant populations.

\section{Materials and methods}

\section{Samples}

We collected nasal turbinate bone samples (Wisely et al. 2004) from 321 historical (primarily 1850-1940) red fox specimens at the National Museum of Natural History in Washington, D.C. (USNM; $n=285$ ), Museum of Vertebrate Zoology at the University of California in Berkeley (MVZ; $n=21$ ), Burke Museum at the University of Washington in Seattle (UWBM; $n=7,1974-$ 1983), Museum of Wildlife and Fisheries Biology at the University of California in Davis (WFB; $n$ = 3), and the collection of L. Dalén at the University of Stockholm $(n=5)$. Specimens used in our analyses were collected in North America within the geographical range of indigenous red foxes 
prior to European settlement (Seton 1929; Churcher 1959; Aubry 1983; Kamler \& Ballard 2002) and in Eurasia. Because nonnative lineages of the red fox occur in many regions of North America (Kamler \& Ballard 2002), we were intentionally conservative in delineating the geographical and temporal limits of our North American samples. For specimens from the Rocky Mountains, Cascade Range, and Sierra Nevada in the western contiguous USA (hereafter, the Western mountains), we included only specimens with precise collecting localities ( $<10 \mathrm{~km}$ radius) that were obtained at relatively high elevations; i.e. those that fell on or above the lower $95 \%$ confidence interval around the regression line describing elevation vs. latitude for available specimens. Due to potentially confounding variation in ecological and environmental conditions between the Rocky Mountains and the more coastal Cascade Range and Sierra Nevada, we conducted separate regression analyses for each of these montane systems. By restricting our sampling this way, our results provide the essential baseline information needed to resolve longstanding controversies about the origin and genetic affinities of red fox populations in other portions of their North American range (Kamler \& Ballard 2002).

Geographical units (hereafter, populations) were designated according to the dispersion of sampling sites as: Europe (Sweden, Great Britain, Germany, Italy, and Spain), Asia (eastern Siberia, Mongolia, and China), Alaska (Alaska and the Yukon near the Alaska border), Western Canada (the Yukon near the British Columbia border, Northwest Territories, Alberta, and British Columbia), Central Canada (Manitoba), Eastern Canada (Ontario, Québec, and Newfoundland and Labrador), Rocky Mountains (Idaho, Montana, Wyoming, Utah, Colorado, and New Mexico), Cascade Range (Washington and Oregon), and Sierra Nevada (California). 


\section{Laboratory procedures}

We extracted DNA from 285 tissue samples at Kansas State University using phenol-chloroform extraction procedures described in Wisely et al. (2004). To avoid contamination of historical samples with modern DNA and polymerase chain reaction (PCR) product, we extracted DNA in a separate genetics laboratory designated exclusively for ancient DNA, using rigorous protocols and multiple negative controls (Miller et al. 2002). All personnel entering this facility showered prior to entry and wore protective apparel dedicated to the laboratory. All PCR amplification and downstream applications were conducted in a building separate from the ancient DNA laboratory. The remaining 36 DNA samples were extracted at the Universities of California in Davis and Los Angeles using procedures described previously (Perrine et al. 2007).

\section{PCR amplification and sequencing}

We amplified the $5^{\prime}$ portion of the cytochrome $b$ gene (403 bp) using primers RF14724 and RF15149; for potentially degraded samples, we amplified this region in two fragments using the primer pairs RF14724/RFCYTB3R and RFCYTBBF/RF15149 (Perrine et al. 2007). At Kansas State University, we amplified DNA in a total volume of $25 \mu \mathrm{L}$, consisting of $1 \mu \mathrm{L}$ DNA extract, $1 \times$ PCR buffer, $3 \mathrm{~mm}$ McCl2, $0.2 \mathrm{~mm}$ dNTPs, $2.2 \mu \mathrm{g} / \mu \mathrm{l} \mathrm{BSA}, 0.5 \mu \mathrm{m}$ of each primer and $1 \mathrm{U}$ of AmpliTaq Gold (Applied Biosystems). We set cycle conditions at $94{ }^{\circ} \mathrm{C}$ for 10 min, followed by 40 cycles of $94{ }^{\circ} \mathrm{C}$ for $45 \mathrm{~s}, 50^{\circ} \mathrm{C}$ for $45 \mathrm{~s}$ and $72{ }^{\circ} \mathrm{C}$ for $45 \mathrm{~s}$; followed by a 10 -min extension period at $72{ }^{\circ} \mathrm{C}$. We amplified a 337-340 bp region of the D-loop using primers VVDL1 (5'TCCCCAAGACTCAAGGAAGA-3') and VVDL6 (5'- CAGAATGGCCCTGAGGTAAG-3'); reaction mixtures were the same as above. Cycle conditions were as for cytochrome $b$ but the 
annealing temperature was $50-55^{\circ} \mathrm{C}$. PCRs and conditions for samples analysed at the University of California were as described in Perrine et al. (2007).

We purified and sequenced PCR products, generally in both directions, as described previously (Perrine et al. 2007). When sequences had discrepancies, we re-amplified and resequenced them if possible. We deposited sequences in the EMBL/GenBank/DDBJ nucleotide database (Accession nos FJ830756-FJ830829, FJ840491).

\section{Data analyses}

We based our analyses on a 354-bp portion of the cytochrome $b$ gene (see Perrine et al. 2007) and a 342-bp portion (including insertions and deletions) of the D-loop. We translated cytochrome $b$ sequences to amino acid sequences to ensure they encoded for a continuous polypeptide. We BLAsT-searched haplotypes (Altschul et al. 1990) and compared them to homologous sequences reported by Frati et al. (1998; cytochrome b) and Valiere et al. (2003; Dloop).

We used both graphical and statistical methods of data analysis. The more traditional graphical approaches, including nested clade analysis, are powerful tools for detecting breaks between discrete populations when they exist (Avise et al. 1987; Templeton 2008). Although some have appropriately criticized graphical approaches for their propensity to detect spurious patterns (Beaumont \& Panchal 2008; Petit 2008), we minimized the likelihood of such errors. Because our analyses were conducted within an explicitly hypothesis-driven context, rather than an exploratory one, type I errors were unlikely to occur, as they are random and not biased toward any particular scenario (e.g. Irwin 2002). Additionally, such type I errors are likely to occur primarily for low-mobility species and when sampling is not representative (Irwin 2002). Red foxes (including females) are long-distance dispersers (Allen \& Sargeant 1993) and our sampling, although more intensive in western North 
America, was conducted throughout the presumed presettlement distribution of indigenous red foxes in North America. Another important criticism of graphical approaches has been that they fail to consider the potential effects of stochasticity on resulting patterns, i.e. that the 'best' tree correctly reflects genealogical history (Hey \& Machado 2003). Therefore, to better differentiate between incomplete lineage sorting vs. gene flow, we also used a model-based statistical approach based on Markov chain Monte Carlo (MCMC) simulated ranges of genealogies to obtain maximum-likelihood estimates of splitting time, gene flow, and population size, along with posterior density functions (Hey \& Nielsen 2007). [Correction added after online publication 27 May 2009: in the preceding sentence the reference citation was corrected.]

\section{Phylogenetic and geographical analyses}

We conducted phylogenetic analyses for cytochrome $b$ and D-loop sequences separately. We used Arlequin 3.1 (Schneider et al. 2000) to estimate haplotype and nucleotide diversity, and to generate a matrix of pairwise FST estimates (Weir \& Cockerham 1984) based on haplotype frequencies. We also estimated pairwise $\Phi S T$ to incorporate pairwise differences between haplotypes (Nei \& Li 1979). We evaluated statistical significance $(\alpha=0.05$ ) based on 1000 permutations, then corrected for multiple tests using the sequential Bonferroni method (Rice 1989).

We described relationships among haplotypes using the median-joining network (Bandelt et al. 1999) in Network 4.2.0.1 (www.fluxus-engineering.com). The average mutation rate for cytochrome $b$ in canids has been estimated at approximately $2.8 \%$ per $10^{6}$ generations, based on independent calibration with the fossil record (Wayne et al. 1997). Assuming a generation time of 1 year in red foxes (Lloyd 1980), we expected a mutation to occur every 101000 years on average in a 354-bp sequence. Similarly, we estimated D-loop mutation rates at $17.75 \%$ per $10^{6}$ generations (Savolainen et al. 2002), with an expected mutation every 16473 years in a 342-bp sequence. We used these 
mutation rates to estimate divergence times in terms of the average number of mutations (rho) separating ancestral and descendent haplotypes (Forster et al. 1996; Saillard et al. 2000), calculated in Network 4.2.0.1.

We constructed phylogenetic trees using maximum likelihood (ML) in PAUP* 4.0 Beta version 10 (Swofford 2001), and calculated bootstrap support at the nodes from 100 replicates. We used Bayesian procedures to infer phylogeny based on MCMC sampling conducted in MrBayes 3.1.2 (Ronquist \& Huelsenbeck 2003). We ran the model for $10^{6}$ generations, with four MCMC simulations running simultaneously, and sampled one tree every 100 generations. We discarded the first 1000 trees as burn-in, and estimated Bayesian posterior probabilities (BPP) on the 50\% majority rule consensus of the remaining trees. We used a Hasegawa- Kishino-Yano (HKY) model of DNA substitution (Hasegawa et al. 1985) and the gamma distribution shape (HKY + G model, base frequencies of $\mathrm{A}=0.2783, \mathrm{C}=0.2985, \mathrm{G}=0.1485, \mathrm{~T}=0.3106$, transition to transversion ratio $=$ 8.790, $\mathrm{G}=0.3934$ ) determined using MrModeltest 2.2 (Nylander 2004), to analyse the cytochrome $b$ data set in both ML and Bayesian analyses. For both ML and Bayesian analyses of D-loop haplotypes, we used the general time-reversible model of DNA substitution, proportion of invariable sites, and shape of the gamma distribution [GTR $+\mathrm{I}+\mathrm{G}$ model, base frequencies of $\mathrm{A}=0.2834, \mathrm{C}=$ $0.2653, \mathrm{G}=0.1474, \mathrm{~T}=0.3039$, rate matrix $=(1.4928,22.2561,0.5702,0.1511,7.5004), \mathrm{I}=0.6114$, $\mathrm{G}=0.6327$ determined using MrModeltest 2.2. We used the swift fox [Vulpes velox; cytochrome $b$, L11731, Mercure et al. (1993); D-loop, AF036472, Maldonado et al. (1997)] as our outgroup.

We conducted nested clade analyses (NCA; Templeton 1998) using the median-joining networks described above, except that we removed alternative links deemed implausible based on the phylogenetic tree and strong bootstrap support. We defined nested clades based on established rules (Templeton et al. 1987; Templeton \& Sing 1993), except that we decided ambiguities in 
favour of clades supported by bootstrap analyses. We conducted the NCA using GeoDis 2.4 (Posada et al. 2000) and Templeton’s (2004) inference key.

For geographical analyses, we began by using sAmovA (version 1.0) to evaluate population structure independent of our hypotheses (Excoffier et al. 1992; Dupanloup et al. 2002). We assumed that the numbers of geographical groupings $(K)$ ranged from 2 to 4 for both cytochrome $b$ and Dloop data sets. Because the cytochrome $b$ marker evolves slower than the D-loop, we used the cytochrome $b$ data set on a worldwide scale, but restricted use of the D-loop data set to North American samples. The use of multiple $K$ levels enabled us to investigate the extent to which geographical units were nested to better elucidate hierarchical patterns of population structure. We evaluated the degree to which population genetic differences could be explained by isolation by distance in Arlequin 3.1 using Mantel tests between pairwise ФST and geographical distances.

Based on geographical groupings resulting from sAmovA, we used MCMC-based simulations in the program IMa to assess isolation-with-migration and isolation-with-nomigration models and to produce maximum-likelihood estimates and confidence intervals for splitting times, effective population sizes, and gene flow in each direction (Hey \& Nielsen 2007). We employed the HKY model of substitution and the D-loop data set for this analysis. We began with multiple runs of $10^{3}$ steps (following $10^{5}$ iterations as burn-in) to assess mixing and to narrow the range of parameter space, after which we ran two independent (different random seeds) runs of $10^{6}$ steps in MCMC mode. Otherwise, we did not find it necessary to alter program default settings. Consistent marginal peak locations (parameter estimates) with unimodal likelihood curves approaching zero on both ends indicated reasonable sampling of trees $\left(n=10^{3}\right)$, which were then used in 'LoadTree' mode to estimate joint distributions and final parameter estimates and credibility intervals (see Hey \& Nielsen 2007 for details). 
IMa cannot be used to assess population growth except when it is reflected in discrete size differences between the two descendent populations relative to the ancestral one, and could not necessarily discern between a longer divergence time with gene flow vs. a shorter divergence time with no gene flow. Therefore, to aid in differentiating these scenarios, we used a Bayesian coalescentbased approach to infer the timing of demographic changes. We used standard MCMC sampling to estimate the posterior distribution of effective population size through time using the sequence data with an HKY model of substitution, and specified a Bayesian skyline plot (Drummond et al. 2005) as the demographic model in BEAsT 1.4 (Drummond \& Rambaut 2007). In contrast to IMa, this flexible model makes no a priori assumptions about the demographic scenario of a population; the coalescent nature of the method allows simultaneous estimation of multiple parameters. We ran the analysis for $10^{6}$ iterations, treating the first $10^{5}$ iterations as burn-in, then subsequently sampling genealogies and model parameters every $10^{3}$ generations post burn-in. We reran the analysis until each scale factor was optimized to the criteria for acceptance in the program's documentation. We also tested for population growth by calculating Fu's FS (Fu 1997) in DnaSP 4.50 (Rozas et al. 2003) for different phylogenetic subunits as indicated by our haplotype networks and phylogenetic trees. Fu's FS uses information from haplotype distribution to detect population growth. Populations that have experienced recent expansion show significant deviations from the null hypothesis.

\section{Results}

\section{Sequence data}

We obtained complete cytochrome $b$ sequences (354 bp) from 220 of 321 samples, and partial sequences (221 or 145 bp) from an additional 40 samples. We used only complete sequences for statistical analyses, except those conducted with programs Network, IMa, and BEAsT, which also included partial cytochrome $b$ sequences. The complete sequence contained 24 transitions and 5 
transversions, resulting in 29 haplotypes, 10 of which had been reported previously (Frati et al. 1998; Perrine et al. 2007; Table 1). We obtained a 342-bp D-loop sequence from 174 samples. This sequence included 50 substitutions (39 transitions and 11 transversions) and 7 insertions or deletions, resulting in 54 haplotypes, 2 of which had been published previously (Valiere et al. 2003; Table 2).

\section{Phylogenetic subdivision and nested-clade analyses}

The cytochrome $b$ median-joining network divided the haplotypes into two distinct clades, for which the NCA indicated allopatric fragmentation (Fig. 1); this division was also supported by Bayesian and ML analyses (Fig. 2; 0.82 BPP, 67\% ML). The Holarctic clade included primarily Eurasian, Alaskan, and Western Canadian specimens, whereas all specimens in the Nearctic clade were from North America. None of the Holarctic clade haplotypes occurred in both North America and Eurasia, and subclades were largely concordant with the two continents, providing additional support for allopatric fragmentation. None of the haplotypes we found in North America have been reported from Europe. The Northwestern subclade showed evidence of restricted gene flow and isolation by distance (a finer-scale NCA for cytochrome $b$ data is presented in Fig. S1, Supporting information). Along with the estimate for coalescence of this clade at the G haplotype (rho \pm SD $=0.56897 \pm$ 0.23132, corresponding to $57466 \pm 23363 \mathrm{BP}$ ), these patterns indicate an initial expansion in the Northwest followed by a period of stabilization. The majority (32/34) of Eurasian samples shared a single common base change (a/g at nucleotide 294 in the cytochrome $b$ sequence) distinguishing

them from haplotype G. The two remaining samples from China and Mongolia were the only occurrences of haplotype W, which differed from haplotype $\mathrm{G}$ by a different base change (t/c at nucleotide 114). [Table 1] 
The Nearctic clade included samples from the Western mountains and Central and Eastern Canada, consistent with a pattern of restricted gene flow among subclades indicative of a stable population. The widespread occurrence of the basal haplotype (A) suggests an initial population expansion. However, one clade subdivision primarily associated with the Cascade Range exhibited evidence of more recent range expansion from the Cascade Range to the Rocky Mountains, and another clade subdivision was primarily associated with Central and Eastern Canada (Fig. S1). We estimated coalescence of the Nearctic clade to the basal haplotype (A) at $54594 \pm 30600$ BP, which represents a minimum estimate of colonization time. We estimated coalescence of the Nearctic clade to the basal Holarctic clade haplotype (G) at $279692 \pm 124436$ BP, which provides an estimate of divergence time between these clades. Two haplotypes previously reported from Austria (GenBank nos Z80974, Z80978; Frati et al. 1998) contained two base pairs otherwise unique to the Nearctic clade and one base pair otherwise unique to the Holarctic clade, suggesting that the Holarctic and Nearctic clades diverged in Eurasia and reached North America independently. We incorporated the sequences from Frati et al. (1998) into a network (not shown) and used this comprehensive data set to estimate coalescence of the Nearctic and Holarctic clades at $408461 \pm 139525 \mathrm{BP}$, indicating a somewhat more ancient divergence time.

Analyses of the D-loop data set also resulted in distinct Holarctic and Nearctic clades (Fig. 3) that were completely concordant with their cytochrome $b$ counterparts (Fig. 2). As with cytochrome $b$ data, the D-loop Holarctic and Nearctic clades showed a clear distinction (1 BPP, 88\% ML; Fig. 3). All North American D-loop haplotypes in the Holarctic clade were contained within three divisions of the Beringian and Holarctic subclades (Fig. S2, Supporting information) that were largely concordant with continental distributions, and also showed a pattern of allopatric fragmentation. We estimated that North American haplotypes in the Holarctic clade shared a common ancestor 56355 
\pm 18436 BP. The Nearctic clade coalesced an estimated $90209 \pm 22531$ BP, suggesting a comparable but somewhat earlier upper limit to the colonization time of southern North America than was indicated with cytochrome $b$.

As expected, we obtained finer resolution of substructure within the Nearctic clade using the faster-evolving, non-encoding D-loop region. The Nearctic clade was divided into three distinct, statistically supported subclades: the Eastern (0.99 BPP, 78\% ML), Widespread (0.99 BPP, 74\% ML) and Mountain (0.99 BPP, 81\% ML) subclades (Figs 3 and 4). The Eastern subclade showed a pattern of restricted gene flow and isolation by distance, suggesting long-term presence in eastern Canada. We estimated that the Eastern subclade was $23062 \pm 14024$ years old. The Mountain subclade was restricted almost exclusively to specimens from the Western mountains, and we estimated it to be $17276 \pm 6302$ years old. There was a pattern of allopatric fragmentation within the Mountain subclade, and a (nested) portion of this subclade that contained primarily specimens from the Cascade Range (but also some from the Rocky Mountains) with a signature of continuous range expansion (Fig. S2). Haplotypes in the Widespread subclade shared a common ancestor 43 $928 \pm 17121$ BP. [Table 2]

\section{Structure of red fox populations}

Based on the cytochrome $b$ data set from our worldwide sample, sAmovA identified the most fundamental division (i.e. $K=2$ ) as (i) Eurasia, Alaska, and Western Canada and (ii) all other North American populations (Table 3), which reflects the geographical distribution of Holarctic and Nearctic haplotypes (Fig. 5). Based on both D-loop and cytochrome $b$ data, sAMOVA identified the three major groupings in North America as (i) Alaska and Western Canada; (ii) Central Canada and Eastern Canada; and (iii) Rocky Mountains, Cascade Range, and Sierra Nevada (Table 3, Fig. 5). In general, the (DCT values (all statistically significant) using cytochrome $b$ were similar among the 
three levels of $K$, suggesting they were equally correct; i.e. that the population structure was hierarchical. However, the (DCT values based on D-loop data were higher for the $K=3$ and 4 levels than for the $K=2$ level, which likely indicates the poor ability of D-loop data to distinguish moderate vs. deeper levels of divergence between clades (Holarctic vs. Nearctic) and subclades (primarily Eastern vs. Mountain). Analysis of D-loop data at $K=4$, which was equally well supported as at the $K=3$ level, separated the Cascade Range from the other two Western mountain populations. [Figure 1] [Figure 2]

We found a low and nonsignificant level of differentiation (pairwise (DST) between Europe and Asia for cytochrome $b$ data, with the most common haplotypes occurring from Italy and Sweden to eastern Siberia (Table 4). Europe and Asia had low levels of divergence from Western Canada and Alaska for D-loop data (Table 5), which is also supported by the close genetic similarity of Eurasian and North American Holarctic haplotypes represented in the network (Fig. S2). Based on both cytochrome $b$ and D-loop data, European populations were most differentiated from those in Central Canada, Eastern Canada, and the Western mountains, which contained primarily Nearctic haplotypes. Alaska also had relatively high levels of differentiation from Central Canada, Eastern Canada, and the Western mountains for both data sets. Eastern Canada was highly differentiated from all populations except Central Canada. [Figure 3]

The three Western mountain populations comprised predominantly Nearctic clade cytochrome $b$ haplotypes and Mountain subclade D-loop haplotypes (Figs 1, 4 and 5). These populations shared the basal cytochrome $b$ haplotype from the Nearctic clade (A) and also the basal D-loop haplotype from the Mountain subclade (19). For D-loop data, the Rocky Mountain population was not significantly differentiated from the Sierra Nevada population but was from the Cascade Range population, although the difference was relatively small. For both data sets, the Cascade Range and Rocky 
Mountain populations were highly differentiated from the adjacent Western Canada population (Tables 4 and 5). [Table 3] [Figure 4] [Table 4] [Table 5] [Figure 5] [Table 6] [Figure 6]

Demographic analyses

Although samova indicated strong differentiation of the Rocky Mountain, Cascade Range, and Sierra Nevada populations (Western mountains) from those in Central and Eastern Canada (Eastern), OCT cannot be used to determine the age of this split or to distinguish between incomplete lineage sorting and gene flow. Therefore, we used IMa to assess the splitting time between Western mountain and Eastern populations, along with estimates of $N_{e}$ associated with each of these and the ancestral population under two demographic models: gene flow between these populations, and no gene flow between them. Both the isolation-with-migration and isolation-only models indicated that the effective population size was substantially larger for the Western mountain populations than the Eastern populations and the ancestral population, which is consistent with an expansion that occurred primarily or entirely in the Western mountains (Table 6). The models differed primarily in the estimated time of this splitting event and in the size of the ancestral population. In the isolation-withmigration model, the split was estimated at 56000 bp from a very small ancestral population. This model indicated asymmetric gene flow, primarily from west to east, consistent with the distribution of the Widespread subclade. However, the credibility intervals were extremely wide for estimates of gene flow (approaching 0 on the low end) and for ancestral population size. Whereas the isolationonly model was supported by well-behaved posterior density functions (and, hence, narrower credibility intervals) for all parameters, the posterior density function for splitting time in the isolationwith-migration model was bimodal and the upper tail remained high, extending to the upper constraint (corresponding to $165000 \mathrm{bp}$ ). The isolation-only model also seemed far more realistic, estimating a 
divergence time of $16000 \mathrm{bp}$ and an ancestral population size of a similar order of magnitude to descendent population estimates. Thus, consistent with the NCA, this analysis indicated that Eastern representatives of the Widespread subclade reflect incomplete lineage sorting.

Scale factors for Bayesian skyline plot analyses were optimized after 5-7 runs. Demographic models constructed from the entire cytochrome $b$ data set, and from each major clade (Holarctic and Nearctic) corroborated the interpretation of the NCA, indicating extensive range expansion by red foxes in North America following the retreat of Wisconsin glaciers (Fig. 6). This expansion was more pronounced in the Holarctic clade than in the Nearctic clade. The rapid mutation rate of the D-loop sequence did not provide the temporal depth needed to distinguish demographic expansion associated with Late Pleistocene/Holocene range expansion. Models for D-loop data sets (not shown) indicated more continuous and gradual range expansion, with little evidence of population responses associated with the last glaciation.

We also found a significant signature of postglacial expansion with Fu's Fs using cytochrome $b$ data in both the Holarctic $(F S=-6.32 ; P=0.016)$ and Nearctic $(F S=-9.03 ; P \leq 0.001)$ clades. When we conducted the same analysis with the faster evolving D-loop data, only the Holarctic clade retained the signature of expansion, indicating more recent expansion in the Holarctic clade than in the Nearctic. When we analysed the cytochrome $b$ Holarctic data set from each continent separately, only the Eurasian subclade had a significant signature of expansion $(F S=-2.03 ; P=$ 0.050), and when we calculated the FS statistic for each of the three Nearctic D-loop subclades separately, only the Mountain subclade had a significant signature of expansion $(F S=-3.27 ; P=$ 0.033). 


\section{Genetic diversity of red fox populations}

We found a slightly higher haplotype diversity but much higher nucleotide diversity in North America than Eurasia for both cytochrome $b$ and D-loop data sets (Tables 7 and 8), reflecting a greater diversity of higher order clades for both mtDNA markers (Figs 1-4). Eastern Canada had relatively low haplotype and nucleotide diversities. Western Canada had the highest nucleotide diversities for both cytochrome $b$ and D-loop haplotypes, due to the admixed nature of the population, with haplotypes in both cytochrome $b$ clades (Fig. 1), two subclades in the Holarctic Dloop clade (Fig. S2), and all three subclades in the Nearctic D-loop clade (Fig. 4). Of the three Western mountain populations, the Rocky Mountains had the highest nucleotide diversity, followed by the Sierra Nevada. For both cytochrome $b$ and D-loop data sets, the Cascade Range had the lowest nucleotide diversity for any population studied, with $>50 \%$ of the samples having a single haplotype ( $\mathrm{O}$ and 24, respectively).

\section{Discussion}

\section{Quaternary zoogeography}

Our results strongly support Aubry’s (1983) two-refugia hypothesis for the Quaternary zoogeography of North American red foxes, and refute the one-refugium hypothesis proposed by Macpherson (1965). Both cytochrome $b$ and D-loop data sets clearly indicate that North America contains two distinct clades: a Holarctic clade represented in Eurasia, Alaska, and western Canada, and a Nearctic clade (divided into the Mountain, Widespread, and Eastern subclades for D-loop data) that is restricted to North America (Figs 1-4). In addition, demographic analyses (NCA, Fu's FS, IMa, and BEAST) consistently indicated rapid population expansion in both Holarctic and Nearctic clades after the retreat of Wisconsin glaciers (figure 6). [Table 7] [Table 8] 
As predicted by the two-refugia hypothesis, the montane red foxes were clearly derived from populations that were isolated in the southern refugium during the last glaciation. Additionally, we estimated that the Mountain subclade diverged from the basal D-loop haplotype (19) $17276 \mathrm{Br}$, which is consistent with their isolation in the Western mountains since the last glaciation. However, northern refugial populations did not spread southeastward across the breadth of Canada; rather, their postglacial expansion appears to have been restricted primarily to Alaska and western Canada (Fig. 5). Although the clinal nature of cranial variation from Alaska across Canada to the eastern seaboard (Churcher 1959) suggests that all Canadian populations may have arisen from the southeastward expansion of northern refugial red foxes across Canada, our results show that central and eastern Canadian populations were derived primarily from southern refugial red foxes. Thus, the observed cline in size among Alaskan and Canadian red foxes (Churcher 1959) did not arise from the stepping-stone colonization of southeastern regions by northern refugial red foxes but rather by populations of relatively large northern refugial red foxes expanding into western Canada and coming into contact with populations of smaller southern refugial red foxes expanding northward into central and eastern Canada. This scenario is also supported by analyses of population differentiation, which provided the strongest support for dividing the North American populations we sampled into three groups: (i) Alaska and Western Canada, (ii) Central and Eastern Canada, and (iii) Rocky Mountains, Cascade Range, and Sierra Nevada (Table 3; Fig. 5).

Implicit in the two-refugia hypothesis is the assumption that descendents of red foxes that initially colonized North America during the Illinoian glaciation (or earlier) would be represented in all modern indigenous populations. However, our estimates of divergence times indicate that the Nearctic clade is much older than the North American component of the Holarctic clade (279 $692-$ 408461 BP vs. 56355 BP, respectively). Consequently, although our results show that southern 
refugial red foxes were remnants of an earlier colonization of northwestern North America that occurred during or before the Illinoian glaciation, the northern refugial red foxes represent a distinct lineage that originated in Asia and re-colonized North America during the Wisconsin glaciation. This finding is also supported by the occurrence of two previously published (Frati et al. 1998) Austrian haplotypes that were intermediate (i.e. potentially ancestral) to both clades. It appears that climatic changes associated with the onset of the Wisconsin glaciation resulted in the extirpation of red foxes in northwestern North America. As the glaciers advanced and isolated all remaining North American red foxes in the southern refugium, Eurasian red foxes re-colonized Alaska and the Yukon via the Bering Land Bridge.

Nested-clade analyses, sAmovA, and IMa unambiguously indicated the differentiation of southern refugial red foxes into two distinct, geographically restricted lineages during the Wisconsin glaciation: one in the West (Mountain subclade), and another in the East (Eastern subclade), both dated at approximately $20000 \mathrm{BP}$. Although we found representatives of a third, more ancient lineage (Widespread subclade) in both regions, we estimated the age of this subclade at twice that of the geographically restricted subclades (Fig. 4); thus, the Widespread subclade likely represents the ancestral population prior to splitting near the height of the last glaciation $\sim 20000 \mathrm{BP}$. The split evident in the NCA was supported by sAmovA, and the time frame suggested for population splitting by rho analyses of the two geographically restricted subclades was similar to that estimated in the isolation-only model in IMa.

These findings were also supported by the occurrence of late-Wisconsin (10 000-40 $000 \mathrm{BP})$ fossils of the red fox in two disjunct regions: the Western mountains and the Appalachian Mountains in the eastern USA (Faunmap Working Group 1994: 366). At the height of the Wisconsin glaciation, intervening areas, including a treeless and windswept desert in the central Great Plains (Mengel 1970), 
were apparently uninhabitable by many forest-dwelling species (Pielou 1991: 71-74). Thus, our findings contribute to a growing body of evidence indicating the existence of multiple lineages in modern populations of boreal mammals that arose from prolonged isolation in forest refugia south of the margin of glacial ice, including the American marten (Martes americana; Graham \& Graham 1994; Carr \& Hicks 1997; Stone et al. 2002), black bear (Ursus americanus; Wooding \& Ward 1997; Stone \& Cook 2000), tree squirrels (Tamiasciurus spp. and Glaucomys spp.; Arbogast 1999; Arbogast et al. 2001), and red-backed voles (Myodes spp.; Cook et al. 2004; Runck \& Cook 2005). For most of these species, modern populations appear to have arisen primarily from the postglacial colonization of northern regions by lineages that were isolated in either the Western mountains or the eastern USA. The creation of an ice-free corridor between the Cordilleran and Laurentide ice sheets during glacial retreat apparently provided a northwest colonization route for lineages isolated in the eastern USA that was not available to those in the Western mountains (see Runck \& Cook 2005). This pattern of postglacial colonization created phylogeographical discontinuities for many boreal species at the southern limit of the Cordilleran ice sheet near the USA/Canada border in the Pacific Northwest that corresponds closely to the northern limit of the Mountain subclade in red foxes (Fig. 5).

The Mountain subclade represents the descendents of red foxes that were isolated in the western portion of the southern refugium during the last glaciation (Fig. 5). The fossil record suggests that at the height of the Wisconsin glaciation, red fox populations in the Western mountains occurred at lower elevations than they currently do (Faunmap Working Group 1994: 366). That distribution is consistent with estimates of tree line lowering by up to $1000 \mathrm{~m}$ in the northwestern USA during the Late Wisconsin, and the occurrence of forests primarily along the base of mountain ranges and in small protected areas (Heusser 1977; Baker 1983; Barnosky et al. 1987; Whitlock 1992). In addition, ice-age 
boreal forests in the southern refugium were apparently much more open in structure than modern spruce (Picea spp.) forests (Cushing 1965; Wright 1981; Jacobson et al. 1987). Presumably, red foxes in the Western mountains tracked these forest conditions as their elevational range contracted up in elevation during glacial retreat. Thus, the subalpine parklands and alpine meadows that modern montane red foxes are largely restricted to (Aubry 1983; Kamler \& Ballard 2002; Perrine 2006) may represent the modern analogue of forest conditions occupied by red foxes in the Western mountains during the last glaciation.

Our results support Aubry's (1983) hypothesis that the montane red foxes were specialized to subalpine and alpine habitat conditions and did not cross intervening habitat areas. Given their longterm isolation and the extreme climatic conditions they occupy, montane red foxes may possess physiological adaptations that other populations lack (Grinnell et al. 1937; Aubry 1984; Swanson et al. 2005). However, recent findings indicate that red foxes from this phylogenetic group occupy lowelevation habitats in northern California (Perrine et al. 2007), suggesting that any such specializations were evolutionarily plastic, and that additional factors may have contributed to their long-term isolation. It is not clear what barriers would have prevented such a wide-ranging and adaptable carnivore as the red fox from moving between the Western mountains and boreal habitats to the north, or the Great Plains to the east, over tens of thousands of years. One possibility is that highelevation boreal habitats in the Western mountains were surrounded historically by habitats saturated with other canids that competitively excluded red foxes. The ranges of North American wolf-like canids shifted throughout the Holocene which may, in turn, have influenced the distributions of smaller canids. This explanation seems especially applicable to the Great Plains, where it is likely that coyotes (Canis latrans) were more abundant historically than during the 20th century, when red foxes began colonizing that area (Kamler \& 
Ballard 2002). Natal habitat-biased dispersal also could have impeded downslope population expansions by montane red foxes. Although such behaviour explains subdivisions (partial restriction of gene flow) between populations of other wide-ranging canids (Geffen et al. 2004; Sacks et al. 2004, 2005, 2008; Pilot et al. 2006), it is unlikely to fully explain the long-term isolation of North American red fox populations.

\section{Taxonomic and conservation implications}

Our findings provide the phylogenetic context needed to evaluate the validity of current taxonomic classifications for the North American red fox (Merriam 1900; Churcher 1959; Hall 1981). We have confirmed Churcher's (1959) hypothesis that Eurasian red foxes are more closely related to populations in Alaska and western Canada than to those in central or eastern Canada or the western mountains. However, the apparent cline across northern North America resulted from secondary contact and incomplete mixing of two distinct lineages, not from isolation by distance within a single lineage, as Churcher assumed. Regardless of how taxonomic questions are ultimately resolved, it is clear that the montane red foxes have remained isolated from all other populations since the last glacial maximum, and there is evidence suggesting that montane populations may have unique ecological or physiological adaptations. Thus, our findings support treating the montane red foxes as evolutionarily distinct. Given the likely impacts of climate change on suitable habitat for high-elevation species in southwestern North America (Lawler et al. 2006), and the documented decline in recent decades of the Sierra Nevada red fox, a state-listed 'threatened' species in California (Perrine et al. 2007), the current status of the montane red foxes is an important conservation concern.

The phylogeography and historical population structure of North American red foxes revealed in this study was based on museum specimens, most of which were collected 80-100 years ago. It is 
important to determine how the patterns reported here may have changed over the past century by analysing modern samples with high-resolution nuclear markers to compare genetic diversity and gene flow among montane populations in both historical and modern eras. Additionally, it is now possible to use genetic data from indigenous populations of red foxes (this study) to investigate the validity of previous hypotheses regarding modern range expansions and human translocations of red foxes (e.g. Fichter \& Williams 1967; Aubry 1984; Lewis et al. 1999; Kamler \& Ballard 2002; Perrine et al. 2007), and the origin of putative non-native populations occurring at low elevations throughout North America.

\section{Acknowledgements}

We thank J. Campos for assistance with sampling, and T. Cipra and A. Mattox for laboratory assistance. The following individuals generously allowed us access to museum specimens in their care: R. Fisher and S. Peurach of the National Museum of Natural History, C. Conroy and E. Lacey of the Museum of Vertebrate Zoology, J. Bradley of the University of Washington Burke Museum, and L. Dalén of the Department of Zoology, Stockholm University. We respectfully acknowledge the posthumous contributions of Aryan Roest of the California Polytechnic State University, who helped refine our understanding of morphological variation in North American red foxes and provided unpublished data on cranial measurements. Lastly, we thank R. Wayne and several anonymous reviewers whose comments and suggestions on previous drafts greatly improved the quality of this manuscript. Partial funding was provided by the USDA Forest Service, Pacific Northwest Research Station and the Kansas State University Ecological Genomics Institute..

\section{References}

Allen SJ, Sargeant SB (1993) Dispersal patterns of red foxes relative to population density. Journal of Wildlife Management, 57, 526- 533. 
Altschul SF, Gish W, Miller W, Myers EW, Lipman DJ (1990) Basic local alignment search tool. Journal of Molecular Biology, 215, 403- 410.

Anderson E (1968) Fauna of the Little Box Elder Cave, Converse County, Wyoming. The Carnivora. University of Colorado Studies, Series in Earth Sciences, 6, 1-59.

Arbogast BS (1999) Mitochondrial DNA phylogeography of the new world flying squirrels (Glaucomys): implications for Pleistocene biogeography. Journal of Mammalogy, 80, 142-155. Arbogast BS, Kenagy GJ (2001) Comparative phylogeography as an integrative approach to historical biogeography. Journal of Biogeography, 28, 819-825.

Arbogast BS, Browne RA, Weigl PD (2001) Evolutionary genetics and Pleistocene biogeography of North American tree squirrels (Tamiasciurus). Journal of Mammalogy, 82, 302-319.

Aubry KB (1983) The Cascade red fox: distribution, morphology, zoogeography and ecology. Dissertation, University of Washington, Seattle, Washington.

Aubry KB (1984) The recent history and present distribution of the red fox in Washington. Northwest Science, 58, 69-79.

Avise JC, Arnold J, Ball RM et al. (1987) Intraspecific phylogeography: the mitochondrial DNA bridge between population genetics and systematics. Annual Review of Ecology and Systematics, 18, 489- 522.

Baker RG (1983) Holocene vegetational history of the western United States. In: Late-Quaternary Environments of the United States, Vol. 2: the Holocene (ed. Wright HE Jr), pp. 109-126. University of Minnesota Press, Minneapolis, Minnesota.

Bandelt H-J, Forster P, Röhl A (1999) Median-joining networks for inferring intraspecific phylogenies. Molecular Biology and Evolution, 16, 37-48. 
Barnosky CW, Anderson PM, Bartlein PJ (1987) The northwestern U.S. during deglaciation: vegetational history and paleoclimatic implications. In: North America and Adjacent Oceans during the Last Deglaciation (eds Ruddiman WF, Wright HE Jr), pp. 289- 321. Geological Society of America, Boulder, Colorado.

Beaumont MA, Panchal M (2008) On the validity of nested clade phylogeographical analysis. Molecular Ecology, 17, 2563-2565.

Carr SM, Hicks SA (1997) Are there two species of marten in North America? Genetic and evolutionary relationships within Martes. In: Martes: Taxonomy, Ecology, Techniques, and Management (eds Proulx G, Bryant HN, Woodward PM), pp. 15-28. Provincial Museum of Alberta, Edmonton.

Churcher CS (1959) The specific status of the New World red fox. Journal of Mammalogy, 40, $513-520$.

Cook JA, Runck AM, Conroy CJ (2004) Historical biogeography at the crossroads of the northern continents: molecular phylogenetics of red-backed voles (Rodentia: Arvicolinae). Molecular Phylogenetics and Evolution, 30, 767-777.

Cushing EJ (1965) Problems in the Quaternary phytogeography of the Great Lakes region. In: The Quaternary of the United States (eds Wright HE Jr, Frey DG), pp. 403-416. Princeton University Press, Princeton, New Jersey.

Drummond AJ, Rambaut A (2007) BEAST: Bayesian evolutionary analysis by sampling trees. BMC Evolutionary Biology, 7, 214.

Drummond AJ, Rambaut A, Shapiro B, Pybus OG (2005) Bayesian coalescent inference of past population dynamics from molecular sequences. Molecular Biology and Evolution, 22, 1185-1192. 
Dupanloup I, Schneider S, Excoffier L (2002) A simulated annealing approach to define the genetic structure of populations. Molecular Ecology, 11, 2571-2581.

Excoffier L, Smouse PE, Quattro JM (1992) Analysis of molecular variance inferred from metric distances among DNA haplotypes: application to human mitochondrial DNA restriction data. Genetics, 131, 479-491.

Faunmap Working Group (1994) FAUNMAP: A Database Documenting Late Quaternary Distributions of Mammal Species in the United States. Illinois State Museum, Scientific Papers, Vol. XXV no. 1, Springfield, Illinois.

Fichter E, Williams R (1967) Distribution and status of the red fox in Idaho. Journal of Mammalogy, 48, 219-230.

Forster P, Harding R, Torroni A, Bandelt H-J (1996) Origin and evolution of Native American mtDNA variation: a reappraisal. American Journal of Human Genetics, 59, 935-945.

Frati F, Hartl GB, Lovari S, Delibes M, Markov G (1998) Quaternary radiation and genetic structure of the red fox Vulpes vulpes in the Mediterranean Basin, as revealed by allozymes and mitochondrial DNA. Journal of Zoology, 245, 43-51.

Fu Y (1997) Statistical tests of neutrality of mutations against population growth, hitchhiking, and background selection. Genetics, 147, 915-925.

Geffen E, Anderson MJ, Wayne RK (2004) Climate and habitat barriers to dispersal in the highly mobile grey wolf. Molecular Ecology, 13, 2481-2490.

Gilmore RM (1946) Mammals in archeological collections from southwestern Pennsylvania. Journal of Mammalogy, 27, 227- 234. 
Graham RW, Graham MA (1994) Late Quaternary distribution of Martes in North America. In: Martens, Sables, and Fishers: Biology and Conservation (eds Buskirk SW, Harestad AS, Raphael MG, Powell RA), pp. 26-58. Cornell University Press, Ithaca, New York.

Grinnell J, Dixon JS, Linsdale JM (1937) Fur-Bearing Mammals of California. University of California Press, Berkeley, California. Guilday JE, Hamilton HW, Anderson E, Parmalee PW (1978) The Baker Bluff cave deposit, Tennessee, and the late Pleistocene faunal gradient. Carnegie Museum of Natural History Bulletin, 11, 1-67.

Guralnick R (2007) Differential effects of past climate warming on mountain and flatland species distributions: a multispecies North American mammal assessment. Global Ecology and Biogeography, 16, 14-23.

Hall ER (1981) The Mammals of North America, 2nd edn. John Wiley \& Sons, New York. Harington C (1977) Pleistocene mammals of the Yukon Territory. Dissertation, University of Alberta, Edmonton.

Hasegawa M, Kishino H, Yano T (1985) Dating of the human-ape splitting by a molecular clock of mitochondrial DNA. Journal of Molecular Evolution, 22, 160-174.

Heusser CJ (1977) Quaternary paleoecology of the Pacific slope of Washington. Quaternary Research, 8, 282-306.

Hey J, Machado CA (2003) The study of structured populations new hope for a difficult and divided science. Nature Reviews Genetics, 4, 535-543.

Hey J, Nielsen R (2007) Integration within the Felsenstein equation for improved Markov chain Monte Carlo methods in population genetics. Proceedings of the National Academy of Sciences, USA, 8, 2785-2790. 
Irwin DE (2002) Phylogeographic breaks without geographic barriers to gene flow. Evolution, 56, 2383-2394.

Jacobson GL Jr, Webb T III, Grimm EC (1987) Patterns and rates of vegetation change during the deglaciation of eastern North America. In: North America and Adjacent Oceans during the Last Deglaciation (eds Ruddiman WF, Wright HE Jr), pp. 277-288. Geological Society of America, Boulder, Colorado.

Kamler JF, Ballard WB (2002) A review of native and nonnative red foxes in North America. Wildlife Society Bulletin, 30, 370-379. Lariviére S, PasitschniakArts M (1996) Vulpes vulpes. Mammalian Species, 537, 1-11.

Lawler JJ, White D, Neilson RP, Blaustein AR (2006) Predicting climate-induced range shifts: model differences and model reliability. Global Change Biology, 12, 1568-1584.

Lewis JC, Sallee KL, Golightly RT Jr (1999) Introduction and range expansion of nonnative red foxes (Vulpes vulpes) in California. American Midland Naturalist, 142, 372-381.

Lloyd HG (1980) The Red Fox. BT Batsford Ltd, London. Macpherson A (1965) The origin of diversity in mammals of the Canadian Arctic tundra. Systematic Zoology, 14, 153-173.

Maldonado JE, Cotera M, Geffen E, Wayne RK (1997) Relationships of the endangered Mexican kit fox (Vulpes macrotis zinseri) to North American arid-land foxes based on mitochondrial DNA sequence data. Southwestern Naturalist, 42, 460-470.

Mengel RM (1970) The North American Central Plains as an isolating agent in bird speciation. In: Pleistocene and Recent Environments of the Central Great Plains (eds Dort W Jr, Jones JK Jr), pp. 279-340. University of Kansas Press, Lawrence, Kansas. 
Mercure A, Ralls K, Koepfli KP, Wayne RK (1993) Genetic subdivisions among small canids: mitochondrial DNA differentiation of swift, kit, and arctic foxes. Evolution, 47, 1313-1328.

Merriam CH (1900) Preliminary revision of the North American red foxes. Proceedings of the Washington Academy of Sciences, 2, 661-676.

Miller CR, Joyce P, Waits LP (2002) Assessing allelic dropout and genotype reliability using maximum likelihood. Genetics, 160, 357-366.

Nei M, Li WH (1979) Mathematical model for studying genetic variation in terms of restriction endonucleases. Proceedings of the National Academy of Sciences, USA, 76, 5269-5273.

Nylander JAA (2004) MrModeltest Version 2. Program distributed by the author. Evolutionary Biology Centre, Uppsala University, Uppsala, Sweden.

Perrine JD (2006) Ecology of the red fox (Vulpes vulpes) in the Lassen Peak region of California, USA. Dissertation, University of California, Berkeley, California.

Perrine JD, Pollinger JP, Sacks BN, Barrett RH, Wayne RK (2007) Genetic evidence for the persistence of the critically endangered Sierra Nevada red fox in California. Conservation Genetics, 8, 1083-1095.

Petit RJ (2008) The coup de grâce for the nested clade phylogeographic analysis? Molecular Ecology, 17, 516-518.

Péwé TL (1975) Quaternary Geology of Alaska. Geological Survey Professional Paper 835. US Government Printing Office, Washington, DC.

Péwé TL, Hopkins DM (1967) Mammal remains of pre-Wisconsin age in Alaska. In: The Bering Land Bridge (ed. Hopkins DM), pp. 266-287. Stanford University Press, Palo Alto, California.

Pielou EC (1991) After the Ice Age: The Return of Life to Glaciated North America. University of Chicago Press, Chicago, Illinois. 
Pilot M, Jedrzejewski W, Branicki W et al. (2006) Ecological factors influence population genetic structure of European gray wolves. Molecular Ecology, 15, 4533-4553.

Pinsof JD, Stewart KM, Seymour KL (1996) Current status of North American Sangamonian local faunas and vertebrate taxa. In: Palaeoecology and Palaeoenvironments of Late Cenozoic Mammals: Tributes to the Career of C.S. (Rufus) Churcher (eds Stewart KM, Seymour KL), pp. 156-190. University of Toronto Press, Ontario.

Posada D, Crandall KA, Templeton AR (2000) GeoDis: a program for the cladistic nested analysis of the geographical distribution of genetic haplotypes. Molecular Ecology, 9, 487-488.

Rice WR (1989) Analyzing tables of statistical tests. Evolution, 43, 223-225.

Ronquist F, Huelsenbeck JP (2003) MrBayes 3: Bayesian phylogenetic inference under mixed models. Bioinformatics, 19, 1572-1574.

Rozas J, Sánchez-De JC, Barrio I, Messeguer X, Rozas R (2003) DnaSP, DNA polymorphism analyses by the coalescent and other methods. Bioinformatics, 19, 2496-2497.

Runck AM, Cook JA (2005) Postglacial expansion of the southern red-backed vole (Clethrionomys gapperi) in North America. Molecular Ecology, 14, 1445-1456.

Sacks BN, Brown SK, Ernest HB (2004) Population structure of California coyotes corresponds to habitat-specific breaks and illuminates species history. Molecular Ecology, 13, 1265- 1275.

Sacks BN, Mitchell BR, Williams CL, Ernest HB (2005) Coyote movements and social structure along a cryptic population genetic subdivision. Molecular Ecology, 14, 1241-1249.

Sacks BN, Bannasch DL, Chomel BB, Ernest HB (2008) Coyotes demonstrate how habitat specialization by individuals of a generalist species can diversify populations in a heterogeneous ecoregion. Molecular Biology and Evolution, 25, 1384-1394. Saillard J, 
Forster P, Lynnerup N, Bandelt H-J, Nørby S (2000) mtDNA variation among Greenland Eskimos: the edge of the Beringian expansion. American Journal of Human Genetics, 67, $718-726$.

Savolainen P, Zhang YP, Luo J, Lundeberg J, Leitner T (2002) Genetic evidence for an East Asian origin of domestic dogs. Science, 298, 1610-1613.

Schneider S, Roessli D, Excoffier L (2000) Arlequin: A Software for Population Genetics Data Analysis, Version 2.000. Genetics and Biometry Laboratory. Department of Anthropology, University of Geneva, Geneva.

Seton ET (1929) Lives of Game Animals, Vol. II, Part II. Doubleday, Doran \& Company, Garden City, New York.

Stone KD, Cook JA (2000) Phylogeography of black bears (Ursus americanus) of the Pacific Northwest. Canadian Journal of Zoology, 78, 1218-1223.

Stone KD, Flynn RW, Cook JA (2002) Post-glacial colonization of northwestern North America by the forest-associated American marten (Martes americana, Mammalia: Carnivora: Mustelidae). Molecular Ecology, 11, 2049-2063.

Swanson BJ, Fuhrmann RT, Crabtree RL (2005) Elevational isolation of red fox populations in the Greater Yellowstone ecosystem. Conservation Genetics, 6, 123-131.

Swofford DL (2001) PAUP: Phylogenetic Analysis Using Parsimony (and Other Methods). Version 4.0b10. Sinauer Associates, Sunderland, Massachusetts.

Templeton AR (1998) Nested clade analyses of phylogeographic data: testing hypotheses about gene flow and population history. Molecular Ecology, 7, 381-397.

Templeton AR (2004) Statistical phylogeography: methods of evaluating and minimizing inference errors. Molecular Ecology, 13, 789-809. 
Templeton AR (2008) Nested clade analysis: an extensively validated method for strong phylogeographic inference. Molecular Ecology, 17, 1877-1880.

Templeton AR, Sing CF (1993) A cladistic-analysis of phenotypic associations with haplotypes inferred from restriction endonuclease mapping. 4. Nested analyses with cladogram uncertainty and recombination. Genetics, 134, 659-669.

Templeton AR, Boerwinkle E, Sing CF (1987) A cladistic analysis of phenotypic associations with haplotypes inferred from restriction endonuclease mapping. I. Basic theory and an analysis of alcohol dehydrogenase activity in Drosophila. Genetics, 117, 343-351.

Valiere N, Fumagalli L, Gielly L et al. (2003) Long-distance wolf recolonization of France and Switzerland inferred from noninvasive genetic sampling over a period of 10 years. Animal Conservation, 6, 83-92.

Wayne RK, Geffen E, Girman DJ, Koepfli KP, Lau LM, Marshall CR (1997) Molecular systematics of the Canidae. Systematic Biology, 46, 622-653.

Weir BS, Cockerham CC (1984) Estimating F-statistics for the analysis of population structure. Evolution, 38, 1358-1370. Whitlock C (1992) Vegetational and climatic history of the Pacific Northwest during the last 20000 years: implications for understanding present-day biodiversity. Northwest Environmental Journal, 8, 5-28.

Wisely SM, Maldonado JE, Fleischer RC (2004) A technique for sampling ancient DNA that minimizes damage to museum specimens. Conservation Genetics, 5, 105-107.

Wooding S, Ward R (1997) Phylogeography and Pleistocene evolution in the North American black bear. Molecular Biology and Evolution, 14, 1096-1105.

Wright HE (1981) Vegetation east of the Rocky Mountains 18000 years ago. Quaternary Research, 15, 113-125. 
Keith Aubry is a Research Wildlife Biologist with the US Forest Service and an Affiliate Professor of Wildlife Science at the University of Washington. His research focuses on the ecology, zoogeography, and conservation genetics of forest carnivores in southern boreal forests of the contiguous US Mark Statham is currently a post doctoral researcher at the UC Davis Veterinary Genetics Laboratory. He is interested in using genetic signatures in current populations to infer phylogeography, endemism, and ancestry. Ben Sacks is an Assistant Professor at Sacramento State University, Adjunct Professor at UC Davis, and director of the Canid Diversity and Conservation laboratory at the UC Davis Veterinary Genetics Laboratory. His research interests relate to conservation, ecology, behaviour, and evolution of wild canids. John Perrine, an Assistant Professor in the Biological Sciences Department at Cal Poly, is primarily interested in mammalian ecology and conservation. Samantha Wisely is an Assistant Professor of Wildlife Biology and the Director of the Conservation Genetics and Molecular Ecology Lab at Kansas State University. Her research focuses on land use and land cover change as it relates to conservation and biogeography.

\section{Supporting information}

Additional supporting information may be found in the online version of this article:

Fig. S1 Complete Cytochrome $b$ Network

Fig. S2 Complete D-loop Network

Please note: Wiley-Blackwell are not responsible for the content or functionality of any supporting materials supplied by the authors. Any queries (other than missing material) should be directed to the corresponding author for the article. 


\section{Appendix}

Museum numbers of red fox specimens used in our analyses. Specimens used only in cytochrome $b$ analyses have the letter code (c), those used only in D-loop analyses have the letter code (d), and those used in both analyses have no letter code

National Museum of Natural History, Washington, D.C. USNM29127, USNM29128, USNM53590, USNM53591, USNM53592, USNM53928, USNM55574 (c), USNM56944 (c), USNM56945, USNM56946 (c), USNM56947, USNM56948 (c), USNM56949, USNM56950, USNM57309, USNM71194 (c), USNM71200 (c), USNM71298, USNM72882 (c), USNM75617, USNM75619, USNM75620, USNM75621, USNM75623 (c), USNM75624, USNM75635, USNM81765 $\quad$ (c), USNM81766 $\quad$ (c), USNM81767 $\quad$ (c), USNM81768, USNM81769, USNM81770, USNM81771, USNM81772 (c), USNM81775, USNM81776 (c), USNM81777, USNM81952, USNM82041, USNM87082, USNM106901, USNM108316, USNM110181, USNM110183, USNM110184, USNM110185, USNM110186, USNM110767 (c), USNM110768, USNM115992, USNM115993 (c), USNM115994, USNM115998 (c), USNM120523 (c), USNM127746, USNM127747, USNM127752, USNM127753 (c), USNM127754, USNM130371, USNM130372, USNM131464, USNM131465, USNM131466, USNM131467, USNM131471, USNM131472, USNM132357, USNM132358, USNM132360, USNM132361, USNM132362, USNM132363 (c), USNM132371, USNM132372 (c), USNM132373 (c), USNM134017 (c), USNM134139 (c), USNM134140, USNM134141, USNM134142, USNM134225, USNM134750 (c), USNM134752, USNM134755 (c), USNM134756, USNM135120, USNM154153, USNM157323, USNM157324, USNM157326, USNM157351, USNM157352, USNM157632, USNM157633 (c), USNM157634 (c), USNM157635 (c), 
USNM159348, USNM159503, USNM159504 (c), USNM168812, USNM175597 (c), USNM175598, USNM175654 (c), USNM175655 (c), USNM175656 (c), USNM175657 (c), USNM175662 (c), USNM175663 (c), USNM177184 (c), USNM188009, USNM188011 (c), USNM188074 (c), USNM188075 (c), USNM188076 (c), USNM188077 (d), USNM200665 (c), USNM200667, USNM200668, USNM200669, USNM200670 (c), USNM200671, USNM200672 (c), USNM200673 (c), USNM200674 (c), USNM200675, USNM200676, USNM200677, USNM200678 (c), USNM200679, USNM200680 (c), USNM200681, USNM200682, USNM200684, USNM200685 (c), USNM200686, USNM203876, USNM203877, USNM203878,

USNM20387 USNM203880, USNM203881, USNM203884 (c), $\quad$ USNM2038 USNM2038 (c), USNM20389 (с), USNM203891, USNM206666, USNM206667, USNM2066 USNM2099 (c), USNM21002 (c), USNM210023 (c), USNM210024, USNM210025, USNM2100 USNM2100 (c), USNM210031, USNM210204 (c), USNM213097, USNM213098, USNM217090, USNM217091， USNM217092, USNM217093, USNM217094, USNM224212, USNM224513, USNM224514, USNM227935, USNM231149, USNM231150, USNM231151, USNM231152 (c), USNM231153, USNM231154, USNM236592 (c), USNM242964, USNM243091, USNM243411, USNM243661 (c), USNM243789, USNM244333 (c), USNM244334 (c), USNM244335, USNM250643 (c), USNM250644, USNM263307 (c), USNM263310 (c), USNM263311 (c), USNM263312 (c), USNM263877, USNM264367, USNM265114 (c), USNM265115, USNM265116 (c), USNM265118 (c), USNM265119, USNM265137, USNM265209, USNM266030, USNM266034 (c), USNM270543 (c), USNM270544 (c), USNM271973, USNM294019, USNM319219 (c), USNM319220, USNMA00790 (c), USNMA00868 (c), USNMA00869 (c), USNMA00870

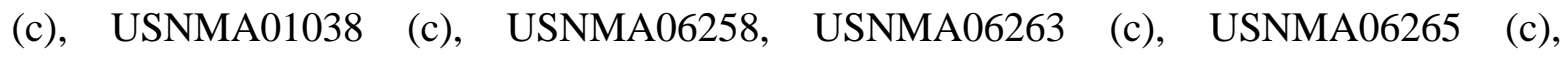
USNMA06509 $\quad$ (c), USNMA07171 $\quad$ (c), USNMA07173 $\quad$ (c), USNMA07174 
USNMA21415 (c), USNMA21418 (c), USNMA23144, USNMA23147, USNMA23150, USNMA23155, USNMA23160 (c), USNMA23167, USNMA23168.

Museum of Vertebrate Zoology, University of California at Berkeley: MVZ16252, MVZ32800, MVZ32809, MVZ33381, MVZ33382, MVZ33472, MVZ33473, MVZ33474, MVZ33586, MVZ33587, MVZ41004, MVZ41468, MVZ44097, MVZ46663, MVZ68857 (c), MVZ68858 (c), MVZ69635, MVZ69636 (c), MVZ89553, MVZ90938.

University of Washington Burke Museum, Seattle: UWBM31868, UWBM32524, UWBM32525, UWBM32554, UWBM32558, UWBM32559, UWBM33375.

Museum of Wildlife and Fisheries Biology, University of California at Davis: WFB9840, WFB9843 (c), WFB9844 (d). 


\begin{tabular}{|c|c|c|c|c|c|c|c|c|c|c|c|c|c|c|c|c|}
\hline Popt & Total & A & $\mathrm{A}^{3}$ & & 4 & A6 & C & D & E2 & $\mathrm{F}$ & F2 & F3 & G & G2 & $\mathbf{J}$ & $\mathbf{N}$ \\
\hline EU & 6 & - & - & & & - & - & - & - & - & - & - & - & - & - & - \\
\hline AS & 21 & - & - & & & - & - & - & - & - & - & - & - & - & - & - \\
\hline $\mathrm{AK}$ & 69 & - & - & & & - & - & - & - & - & - & 1 & 32 & 1 & - & 1 \\
\hline WC & 43 & 8 & 1 & & & - & - & - & - & 2 & 1 & - & 27 & - & - & 1 \\
\hline $\mathrm{CC}$ & 6 & 3 & - & & & - & - & - & - & 2 & 1 & - & - & - & - & - \\
\hline $\mathrm{EC}$ & 20 & - & - & & & - & - & - & 1 & 17 & - & - & 2 & - & - & - \\
\hline $\mathrm{RM}$ & 20 & 15 & 2 & & & 1 & - & - & - & - & - & - & - & - & - & 1 \\
\hline $\mathrm{CR}$ & 13 & 3 & - & & & - & - & - & - & - & - & - & - & - & - & - \\
\hline SN & 22 & 15 & - & & & - & 1 & 1 & - & - & - & - & - & - & 3 & - \\
\hline Total & 220 & 44 & 3 & & & 1 & 1 & 1 & 1 & 21 & 2 & 1 & 61 & 1 & 3 & 3 \\
\hline Popt & 0 & $\mathbf{R}$ & $\mathrm{T}$ & $\mathrm{U}$ & U2 & $\mathrm{U}$ & & U5 & U6 & U7 & $\mathrm{V}$ & v2 & W & $\mathrm{Z}$ & $\mathrm{Z} 2$ & $\mathrm{Z3}$ \\
\hline $\mathrm{EU}$ & - & - & - & 1 & - & 3 & & 1 & 1 & - & - & - & - & - & - & - \\
\hline AS & - & - & - & 9 & 3 & 6 & & - & - & 1 & - & - & 2 & - & - & - \\
\hline AK & - & - & - & - & - & - & & - & - & - & 14 & - & - & 9 & 9 & 2 \\
\hline WC & - & - & - & - & - & - & & - & - & - & 2 & 1 & - & - & - & - \\
\hline $\mathrm{CC}$ & - & - & - & - & - & - & & - & - & - & - & - & - & - & - & - \\
\hline EC & - & - & - & - & - & - & & - & - & - & - & - & - & - & - & - \\
\hline $\mathrm{RM}$ & - & - & - & - & - & - & & - & - & - & - & - & - & - & - & - \\
\hline CR & 9 & - & 1 & - & - & - & & - & - & - & - & - & - & - & - & - \\
\hline SN & 1 & 1 & - & - & - & - & & - & - & - & - & - & - & - & - & - \\
\hline Total & 10 & 1 & 1 & 10 & 3 & 9 & & 1 & 1 & 1 & 16 & 1 & 2 & 9 & 9 & 2 \\
\hline
\end{tabular}

*Haplotypes A, C, D, F, G, J, N, and O are as reported by Perrine et al. (2007); haplotype U is homologous with haplotypes SIC1, SIC2, and B14 reported by Frati et al. (1998); and haplotype W is homologous with SGPFB reported by Yoo et al. (unpublished data; Accession no. DQ498125).

tEU, Europe; AS, Asia; AK, Alaska; WC, Western Canada; CC, Central Canada; EC, Eastern Canada; RM, Rocky Mountains; CR, Cascade Range; SN, Sierra Nevada.

Table 1 Occurrence of 29 cytochrome $b$ haplotypes* among the nine red fox populations sampled

based on 354 bp from 220 specimens. 


\begin{tabular}{|c|c|c|c|c|c|c|c|c|c|c|c|c|c|c|c|c|c|c|c|}
\hline Popt & Total & 3 & 4 & 5 & 7 & 9 & 12 & 17 & 19 & & 24 & 25 & 28 & 29 & 30 & 32 & 34 & 36 & 37 \\
\hline EU & 8 & 1 & 3 & 1 & - & - & - & - & - & & - & - & - & - & - & - & - & - & - \\
\hline AS & 13 & - & - & - & - & - & - & - & - & & - & - & - & - & - & - & - & - & - \\
\hline AK & 49 & - & - & - & 13 & 2 & - & - & - & & - & - & - & - & - & - & - & - & - \\
\hline WC & 28 & - & - & - & 2 & 1 & 1 & - & 1 & & - & - & - & - & - & - & - & - & - \\
\hline CC & 9 & - & - & - & - & 1 & 2 & - & - & & - & - & - & - & - & - & - & - & - \\
\hline $\mathrm{EC}$ & 17 & - & - & - & - & 7 & - & 5 & - & & - & - & - & - & - & - & - & - & - \\
\hline $\mathrm{RM}$ & 17 & - & - & - & 1 & - & - & - & 7 & & - & - & - & - & - & - & - & - & 2 \\
\hline CR & 14 & - & - & - & - & - & - & - & 3 & 3 & 8 & 1 & 2 & - & - & - & - & - & - \\
\hline SN & 19 & - & - & - & - & - & - & - & 6 & & - & - & - & 4 & 1 & 3 & 4 & 1 & - \\
\hline Total & 174 & 1 & 3 & 1 & 16 & 11 & 3 & 5 & 17 & 7 & 8 & 1 & 2 & 4 & 1 & 3 & 4 & 1 & 2 \\
\hline Popt & 38 & 39 & 41 & 42 & 43 & 44 & 45 & 46 & 47 & 48 & 49 & 50 & 5 & 52 & 53 & 54 & 55 & 56 & 57 \\
\hline EU & - & - & - & - & - & - & - & - & - & - & - & - & 1 & - & - & - & - & 1 & 1 \\
\hline AS & - & - & - & - & - & - & - & - & - & 1 & 1 & - & - & - & - & 1 & 3 & - & - \\
\hline $\mathrm{AK}$ & - & 2 & - & - & - & - & - & - & 4 & - & - & 1 & - & - & 3 & - & - & - & - \\
\hline WC & 2 & - & - & - & - & 1 & - & 1 & - & - & - & - & - & - & - & - & - & - & - \\
\hline CC & - & - & - & - & - & - & - & - & - & - & - & - & - & - & - & - & - & - & - \\
\hline $\mathrm{EC}$ & - & - & - & - & - & - & 1 & - & - & - & - & - & - & - & - & - & - & - & - \\
\hline $\mathrm{RM}$ & - & - & 1 & 1 & 1 & - & - & - & - & - & - & - & - & 1 & - & - & - & - & - \\
\hline CR & - & - & - & - & - & - & - & - & - & - & - & - & - & - & - & - & - & - & - \\
\hline SN & - & - & - & - & - & - & - & - & - & - & - & - & - & - & - & - & - & - & - \\
\hline Total & 2 & 2 & 1 & 1 & 1 & 1 & 1 & 1 & 4 & 1 & 1 & 1 & 1 & 1 & 3 & 1 & 3 & 1 & 1 \\
\hline Popt & 58 & 59 & 60 & 61 & 62 & 63 & 64 & 67 & 68 & 6 & & 70 & 71 & 73 & 74 & 75 & 77 & 78 & 79 \\
\hline EU & - & - & - & - & - & - & - & - & - & - & & - & - & - & - & - & - & - & - \\
\hline AS & - & - & - & - & - & - & - & - & - & 1 & & 6 & - & - & - & - & - & - & - \\
\hline $\mathrm{AK}$ & 1 & - & - & 6 & 2 & - & 1 & - & - & - & & - & 1 & - & 1 & 6 & 2 & 4 & - \\
\hline WC & - & - & 1 & - & - & 3 & - & 1 & - & - & & - & - & 14 & - & - & - & - & - \\
\hline $\mathrm{CC}$ & - & - & - & - & - & 4 & - & - & - & - & & - & - & - & - & - & - & - & 2 \\
\hline EC & - & - & - & - & - & 1 & - & - & - & - & & - & - & 1 & - & - & - & - & 2 \\
\hline $\mathrm{RM}$ & - & 2 & - & - & - & - & - & - & 1 & - & & - & - & - & - & - & - & - & - \\
\hline$C R$ & - & - & - & - & - & - & - & - & - & - & & - & - & - & - & - & - & - & - \\
\hline SN & - & - & - & - & - & - & - & - & - & - & & - & - & - & - & - & - & - & - \\
\hline Total & 1 & 2 & 1 & 6 & 2 & 8 & 1 & 1 & 1 & 1 & & 6 & 1 & 15 & 1 & 6 & 2 & 4 & 4 \\
\hline
\end{tabular}

*Haplotypes 4 and 57 are homologous (over $259 \mathrm{bp}$ ) with haplotype F11 reported by Valiere et al. (2003).

tEU, Europe; AS, Asia; AK, Alaska; WC, Western Canada; CC, Central Canada; EC, Eastern Canada; RM, Rocky Mountains; CR, Cascade Range; SN, Sierra Nevada.

Table 2 Occurrence of 54 D-loop haplotypes' among the nine red fox populations sampled based on 342 bp from 174 specimens. 


\begin{tabular}{|c|c|c|c|c|c|c|}
\hline \multirow[b]{2}{*}{ Population } & \multicolumn{3}{|c|}{ Cytochrome $b$} & \multicolumn{3}{|c|}{ D-loop } \\
\hline & $K=2$ & $K=3$ & $K=4$ & $K=2$ & $K=3$ & $K=4$ \\
\hline Eurasia & A & A & A & - & - & - \\
\hline Alaska & A & A & B & A & A & A \\
\hline Western Canada & A & A & B & A & A & A \\
\hline Central Canada & B & B & $\mathrm{C}$ & A & B & B \\
\hline Eastern Canada & B & B & $\mathrm{C}$ & A & B & B \\
\hline Rocky Mountains & B & $\mathrm{C}$ & $\mathrm{D}$ & B & $\mathrm{C}$ & $\mathrm{D}$ \\
\hline Cascade Range & B & $\mathrm{C}$ & $\mathrm{D}$ & B & $\mathrm{C}$ & $\mathrm{C}$ \\
\hline Sierra Nevada & B & $\mathrm{C}$ & $\mathrm{D}$ & B & $\mathrm{C}$ & $\mathrm{D}$ \\
\hline$\Phi_{\mathrm{CT}}$ & 0.59 & 0.58 & 0.61 & 0.36 & 0.50 & 0.49 \\
\hline$P$ & 0.02 & 0.005 & 0.002 & 0.03 & 0.01 & 0.003 \\
\hline
\end{tabular}

Table 3 Best groupings (indicated by letters) based on cytochrome $b$ and D-loop data sets for $K$ $=2$, 3, and 4 groupings, using samova (Dupanloup et al. 2002)

\begin{tabular}{llllllllll} 
Population & Europe & Asia & Alaska & $\begin{array}{l}\text { Western } \\
\text { Canada }\end{array}$ & $\begin{array}{l}\text { Central } \\
\text { Canada }\end{array}$ & $\begin{array}{l}\text { Eastern } \\
\text { Canada }\end{array}$ & $\begin{array}{l}\text { Rocky } \\
\text { Mountains }\end{array}$ & $\begin{array}{l}\text { Cascade } \\
\text { Range }\end{array}$ & $\begin{array}{l}\text { Sierra } \\
\text { Nevada }\end{array}$ \\
\hline Europe & - & 0.04 & $0.49^{*}$ & $0.44^{*}$ & $0.84^{*}$ & $0.82^{*}$ & $0.82^{*}$ & $0.89^{*}$ & $0.88^{*}$ \\
Asia & $0.24^{*}$ & - & $0.36^{*}$ & $0.33^{*}$ & $0.72^{*}$ & $0.74^{*}$ & $0.72^{*}$ & $0.77^{*}$ & $0.77^{*}$ \\
Alaska & $0.25^{*}$ & $0.27^{*}$ & - & $0.16^{*}$ & $0.73^{*}$ & $0.73^{*}$ & $0.71^{*}$ & $0.76^{*}$ & $0.75^{*}$ \\
Western Canada & $0.35^{*}$ & $0.35^{*}$ & $0.35^{*}$ & - & 0.51 & $0.53^{*}$ & $0.50^{*}$ & $0.59^{*}$ & $0.56^{*}$ \\
Central Canada & 0.23 & $0.26^{*}$ & $0.28^{*}$ & $0.37^{*}$ & - & 0.06 & $0.16^{*}$ & $0.54^{*}$ & 0.21 \\
Eastern Canada & $0.56^{*}$ & $0.49^{*}$ & $0.44^{*}$ & $0.54^{*}$ & $0.58^{*}$ & - & $0.39^{*}$ & $0.59^{*}$ & $0.46^{*}$ \\
Rocky Mountains & $0.44^{*}$ & $0.41^{*}$ & $0.39^{*}$ & $0.48^{*}$ & $0.46^{*}$ & $0.64^{*}$ & - & $0.33^{*}$ & 0.04 \\
Cascade Range & $0.38^{*}$ & $0.37^{*}$ & $0.36^{*}$ & $0.45^{*}$ & $0.41^{*}$ & $0.63^{*}$ & $0.53^{*}$ & - & $0.45^{*}$ \\
Sierra Nevada & $0.38^{*}$ & $0.37^{*}$ & $0.36^{*}$ & $0.44^{*}$ & $0.40^{*}$ & $0.59^{*}$ & $0.51^{*}$ & $0.48^{*}$ & -
\end{tabular}

Table 4 Pairwise FST ${ }^{\text {and }}$ OST estimates based on cytochrome $b$ sequence data from the nine red fox populations sampled. Below diagonal, measures are based on haplotype frequencies (FST); above diagonal, estimates incorporate pairwise differences in sequence divergence (OST). Asterisks indicates statistical significance $(a=0.05)$ based on sequential Bonferroni correction for multiple tests (Rice 1989) 


\begin{tabular}{llllllllll} 
Population & Europe & Asia & Alaska & $\begin{array}{l}\text { Western } \\
\text { Canada }\end{array}$ & $\begin{array}{l}\text { Central } \\
\text { Canada }\end{array}$ & $\begin{array}{l}\text { Eastern } \\
\text { Canada }\end{array}$ & $\begin{array}{l}\text { Rocky } \\
\text { Mountains }\end{array}$ & $\begin{array}{l}\text { Cascade } \\
\text { Range }\end{array}$ & $\begin{array}{l}\text { Sierra } \\
\text { Nevada }\end{array}$ \\
\hline Europe & - & 0.22 & $0.23^{*}$ & 0.16 & $0.63^{*}$ & $0.69^{*}$ & $0.56^{*}$ & $0.84^{*}$ & $0.68^{*}$ \\
Asia & 0.17 & - & $0.27^{*}$ & $0.25^{*}$ & $0.53^{*}$ & $0.57^{*}$ & $0.49^{*}$ & $0.73^{*}$ & $0.55^{*}$ \\
Alaska & 0.11 & $0.16^{*}$ & - & $0.17^{*}$ & $0.59^{*}$ & $0.59^{*}$ & $0.55^{*}$ & $0.70^{*}$ & $0.60^{*}$ \\
Western Canada & $0.19^{*}$ & $0.24^{*}$ & $0.17^{*}$ & - & $0.44^{*}$ & $0.49^{*}$ & $0.45^{*}$ & $0.64^{*}$ & $0.51^{*}$ \\
Central Canada & 0.17 & $0.23^{*}$ & $0.15^{*}$ & 0.24 & - & 0.12 & $0.45^{*}$ & $0.78^{*}$ & $0.50^{*}$ \\
Eastern Canada & 0.18 & $0.23^{*}$ & $0.16^{*}$ & $0.25^{*}$ & $0.23^{*}$ & - & $0.51^{*}$ & $0.80^{*}$ & $0.55^{*}$ \\
Rocky Mountains & 0.15 & $0.21^{*}$ & $0.14^{*}$ & $0.26^{*}$ & $0.21^{*}$ & $0.21^{*}$ & - & 0.20 & 0.04 \\
Cascade Range & $0.22^{*}$ & $0.27^{*}$ & $0.19^{*}$ & $0.28^{*}$ & $0.27^{*}$ & $0.27^{*}$ & $0.25^{*}$ & - & $0.27^{*}$ \\
Sierra Nevada & 0.15 & $0.20^{*}$ & $0.14^{*}$ & $0.22^{*}$ & $0.20^{*}$ & $0.20^{*}$ & $0.18^{*}$ & $0.24^{*}$ & -
\end{tabular}

Table 5 Pairwise FST ${ }^{\text {and }}$ OST estimates based on D-loop sequence data from the nine red fox populations sampled. Below diagonal, measures are based on haplotype frequencies (FST); above diagonal, estimates incorporate pairwise differences in sequence divergence (OST). Asterisks indicate statistical significance $(\mathrm{a}=0.05)$ based on sequential Bonferroni correction for multiple tests (Rice 1989)

\begin{tabular}{|c|c|c|c|c|c|c|}
\hline Demographic model & $\begin{array}{l}N_{e} \text { Eastern } \\
(\times 1000)\end{array}$ & $\begin{array}{l}N_{e} \text { Western } \\
\text { mountains } \\
(\times 1000)\end{array}$ & $\begin{array}{l}N_{e} \text { ancestral } \\
(\times 1000)\end{array}$ & $N_{e} m$ into Eastern & $\begin{array}{l}\mathrm{Ne}_{e} m \text { into } \\
\text { Western } \\
\text { mountains }\end{array}$ & $\begin{array}{l}\text { Splitting time } \\
(\times 1000 \text { years })\end{array}$ \\
\hline Isolation with migration & $36(14,80)$ & $133(80,217)$ & $0.5(0.5,911)$ & $0.50(<0.01,4.96)$ & $0.02(0.01,3.46)$ & $55.6(29.4,164.7)$ \\
\hline Isolation only & $49(21,103)$ & $171(97,301)$ & $105(45,244)$ & - & - & $15.7(8.2,26.1)$ \\
\hline
\end{tabular}

Table 6 IMa joint estimates of $N e(\theta / 4 \mu)$, Nem $(\theta \mathrm{m} / 4)$, and population splitting times $(\mathrm{t} / \mu)$ under two demographic models based on D-loop sequences. The $90 \%$ credibility intervals for the posterior distributions of the estimated parameters are indicated in parentheses. 


\begin{tabular}{lrlll} 
Population & $n$ & Haplotypes & $\begin{array}{l}\text { Haplotype } \\
\text { diversity }\end{array}$ & $\begin{array}{l}\text { Nucleotide } \\
\text { diversity }\end{array}$ \\
\hline Europe & 6 & 4 & $0.80 \pm 0.17$ & $0.0034 \pm 0.0029$ \\
Asia & 21 & 5 & $0.74 \pm 0.06$ & $0.0032 \pm 0.0024$ \\
Alaska & 69 & 8 & $0.72 \pm 0.04$ & $0.0045 \pm 0.0030$ \\
Western Canada & 43 & 8 & $0.58 \pm 0.08$ & $0.0061 \pm 0.0038$ \\
Central Canada & 6 & 3 & $0.73 \pm 0.16$ & $0.0026 \pm 0.0024$ \\
Eastern Canada & 20 & 3 & $0.28 \pm 0.12$ & $0.0032 \pm 0.0024$ \\
Rocky Mountains & 20 & 5 & $0.44 \pm 0.13$ & $0.0031 \pm 0.0023$ \\
Cascade Range & 13 & 3 & $0.50 \pm 0.14$ & $0.0015 \pm 0.0015$ \\
Sierra Nevada & 22 & 6 & $0.53 \pm 0.12$ & $0.0019 \pm 0.0017$ \\
Eurasia & 27 & 7 & $0.76 \pm 0.05$ & $0.0034 \pm 0.0025$ \\
North America & 193 & 22 & $0.83 \pm 0.02$ & $0.0089 \pm 0.0051$ \\
All specimens & 220 & 29 & $0.86 \pm 0.01$ & $0.0094 \pm 0.0054$
\end{tabular}

$\overline{\text { Table }} 7$ Haplotype and nucleotide diversities for the cytochrome $b$ sequence of 354 bp for each of the nine populations sampled, all Eurasian specimens, all North American specimens, and all specimens combined.

\begin{tabular}{lrcll} 
Population & $n$ & Haplotypes & $\begin{array}{l}\text { Haplotype } \\
\text { diversity }\end{array}$ & $\begin{array}{l}\text { Nucleotide } \\
\text { diversity }\end{array}$ \\
\hline Europe & 8 & 6 & $0.89 \pm 0.11$ & $0.0109 \pm 0.0070$ \\
Asia & 13 & 6 & $0.77 \pm 0.10$ & $0.0136 \pm 0.0080$ \\
Alaska & 49 & 16 & $0.90 \pm 0.03$ & $0.0118 \pm 0.0066$ \\
Western Canada & 28 & 11 & $0.75 \pm 0.08$ & $0.0168 \pm 0.0092$ \\
Central Canada & 9 & 4 & $0.78 \pm 0.11$ & $0.0133 \pm 0.0082$ \\
Eastern Canada & 17 & 6 & $0.76 \pm 0.08$ & $0.0085 \pm 0.0053$ \\
Rocky Mountains & 17 & 9 & $0.83 \pm 0.08$ & $0.0164 \pm 0.0093$ \\
Cascade Range & 14 & 4 & $0.65 \pm 0.12$ & $0.0023 \pm 0.0020$ \\
Sierra Nevada & 19 & 6 & $0.82 \pm 0.05$ & $0.0150 \pm 0.0085$ \\
Eurasia & 21 & 12 & $0.90 \pm 0.05$ & $0.0144 \pm 0.0082$ \\
North America & 153 & 43 & $0.95 \pm 0.01$ & $0.0232 \pm 0.0120$ \\
All specimens & 174 & 55 & $0.96 \pm 0.01$ & $0.0232 \pm 0.0120$
\end{tabular}

Table 8 Haplotype and nucleotide diversities for the D-loop sequence of 342 bp for each of the nine populations sampled, all Eurasian specimens, all North American specimens, and all specimens combined 


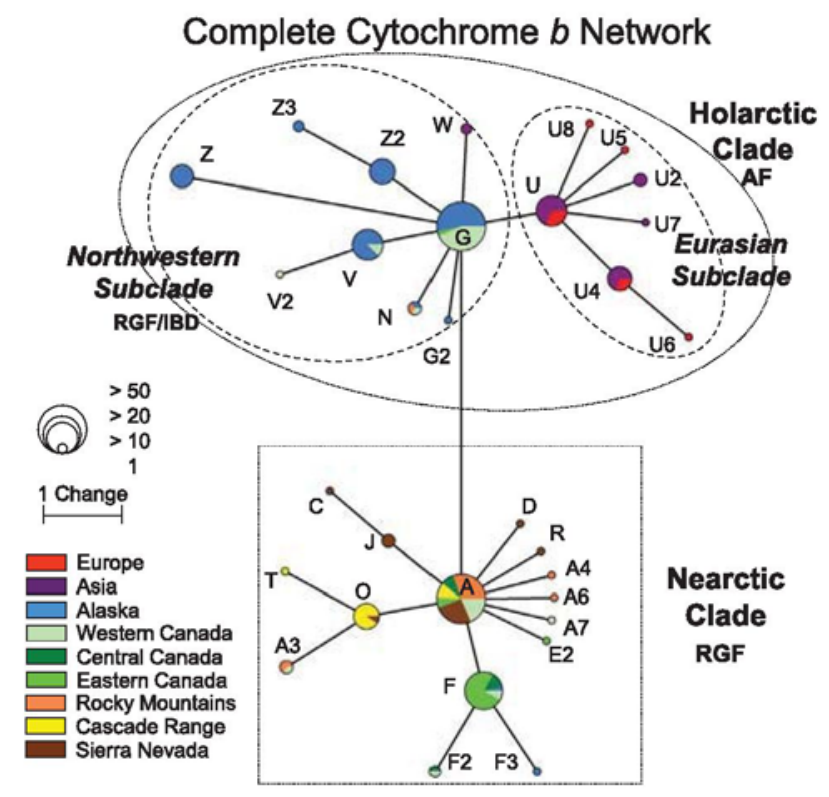

Fig. 1 Cytochrome $b$ median-joining network based on 354 bp for 220 red fox specimens, and partial sequences (one of two cytochrome $b$ fragments) for an additional 40 specimens $(n=260)$. Branch lengths are proportional to the number of substitutions, and circle sizes are proportional to the number of individuals represented. Alternative connections were excluded in favour of connections supported by the maximum-likelihood tree. Clades are indicated with dotted lines and subclades with dashed lines. Tip and interior nested-clade designations are indicated by polygons and ellipses, respectively. The Eurasian subclade is considered interior based on the assumption that it is ancestral. Haplotypes are designated with alphanumeric characters that correspond to those presented in Table 1. Inferences about population history (Templeton 2004) are indicated where statistically significant, including allopatric fragmentation (AF), isolation by distance (IBD), and restricted gene flow (RGF). 


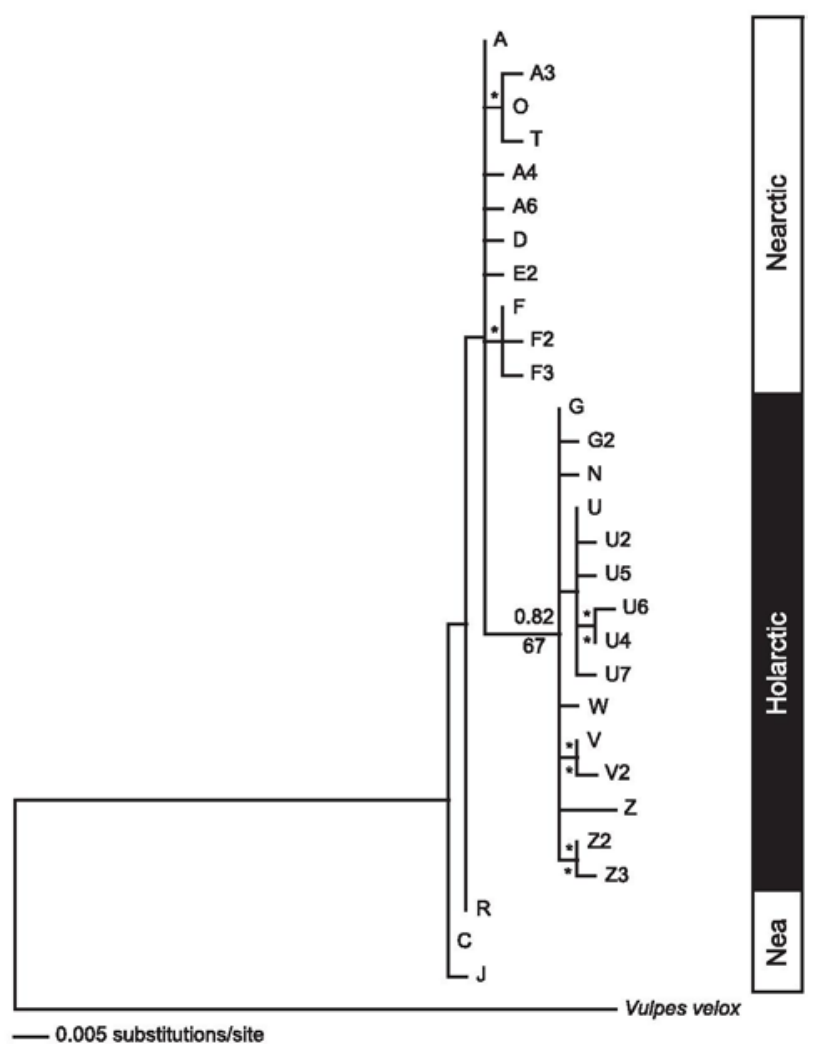

Fig. 2 Maximum-likelihood phylogram of cytochrome $b$ haplotypes constructed under an HKY

+ $\mathrm{G}$ model of evolution based on 354 bp for 220 red fox specimens. Numbers adjacent to the node are Bayesian posterior probabilities (top) and bootstrap values (bottom). Support values > $50 \%$ are shown at the clade level only; nodes within lineages that received $>_{-} 50 \%$ posterior support are indicated with asterisks. We used the swift fox as our outgroup. Shaded boxes on the right indicate clade divisions that correspond to those shown in Figs 1 and 5. 


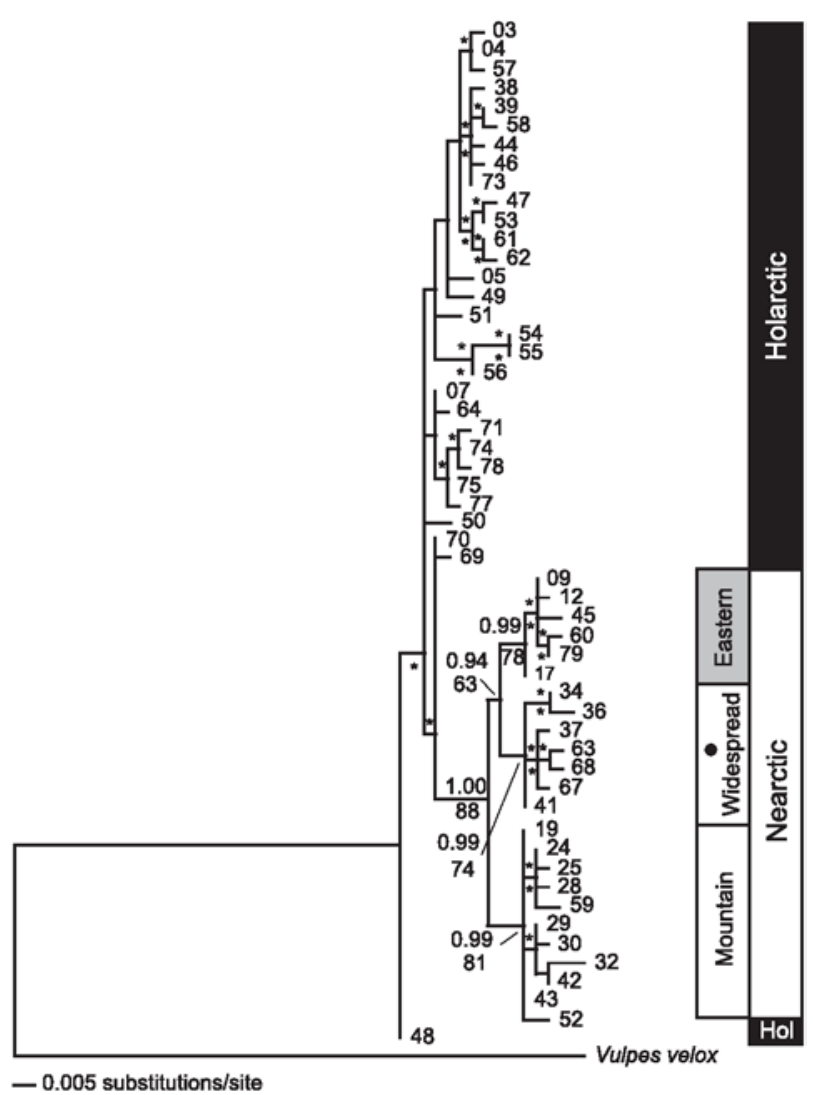

Fig. 3 Maximum-likelihood phylogram of D-loop haplotypes constructed under a GTR + I + G model of evolution based on 342 bp for 174 red fox specimens. Numbers adjacent to the node are Bayesian posterior probabilities (top) and bootstrap values (bottom). Support values >_50\% are shown at the clade level only; nodes within lineages that received $>_{-} 50 \%$ posterior support are indicated with asterisks. We used the swift fox as our outgroup. Shaded boxes on the right indicate clade and subclade divisions that correspond to those shown in Figs 4 and 5. 


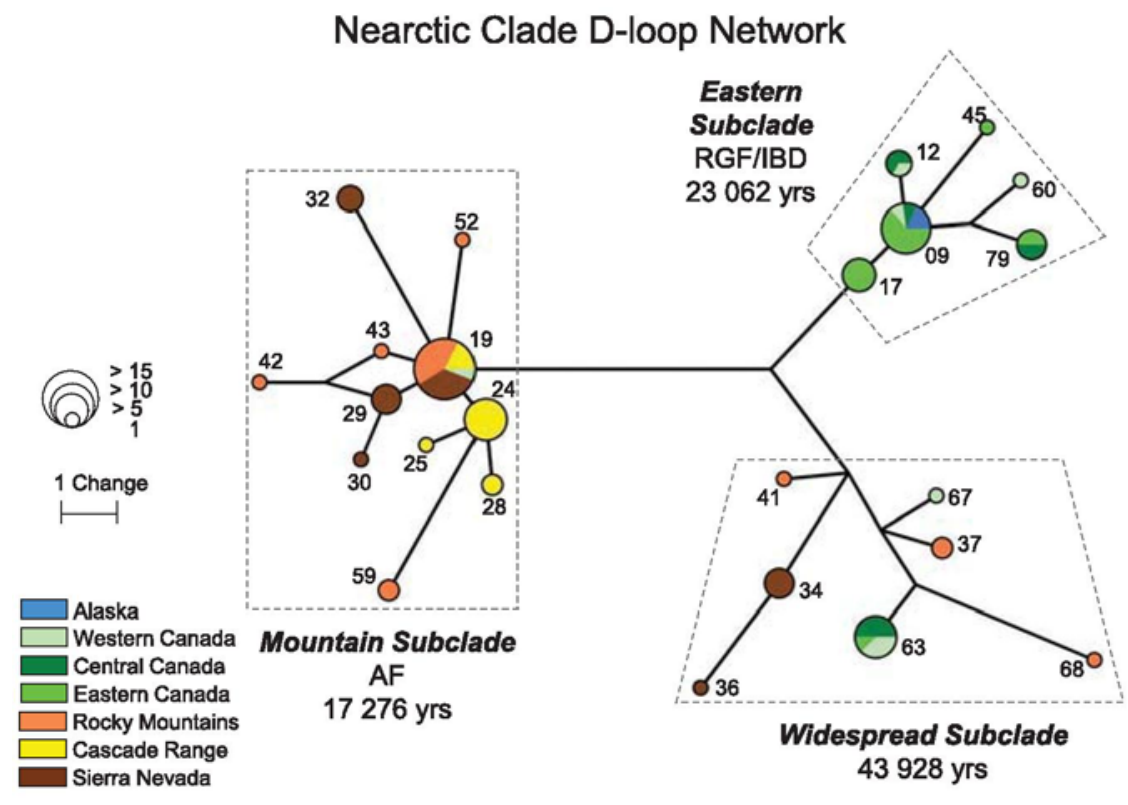

Fig. 4 D-loop median-joining network based on $342 \mathrm{bp}$ for Nearctic clade red fox specimens only $(n=84)$. Sampled populations are indicated with the same colour coding used in Fig. 1. Branch lengths are proportional to the number of substitutions, and circle sizes are proportional to the number of individuals represented. Subclades are indicated with dashed lines and their estimated ages are given. Haplotypes are designated with numbers that correspond to those presented in Table 2. Inferences about population history (Templeton 2004) are indicated where appropriate, including allopatric fragmentation (AF), isolation by distance (IBD), and restricted gene flow (RGF). 
(a)

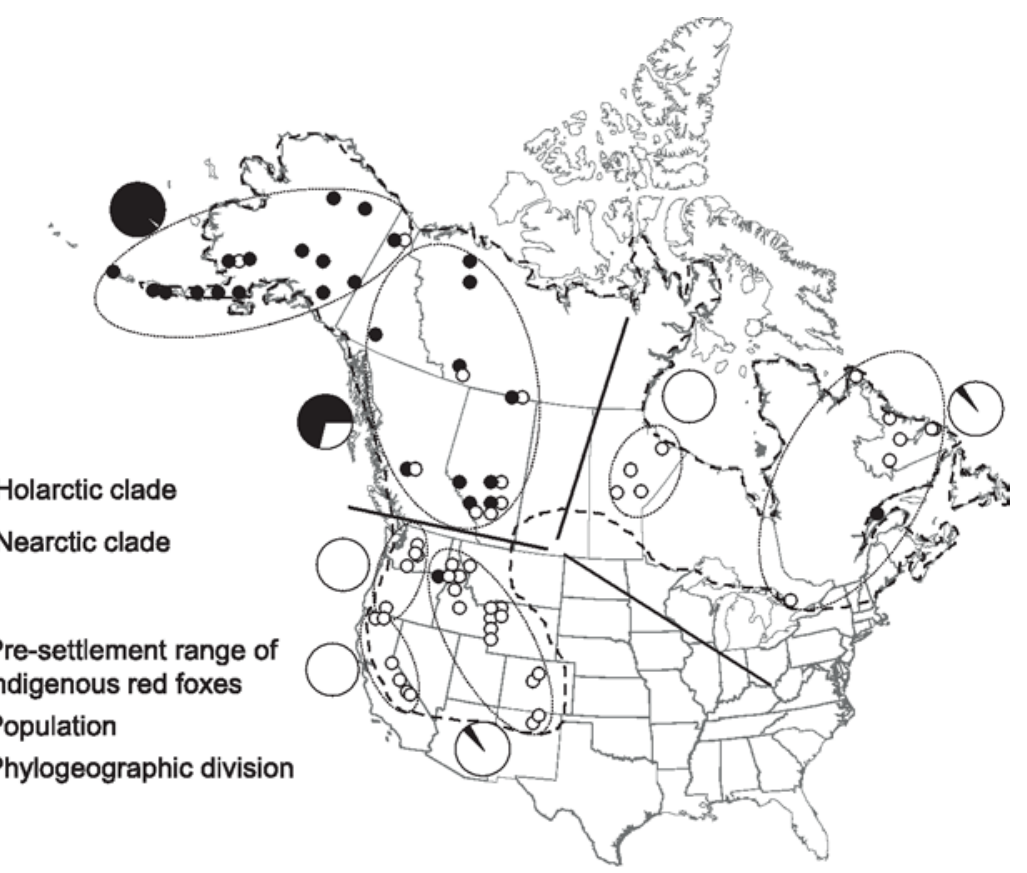

(b)

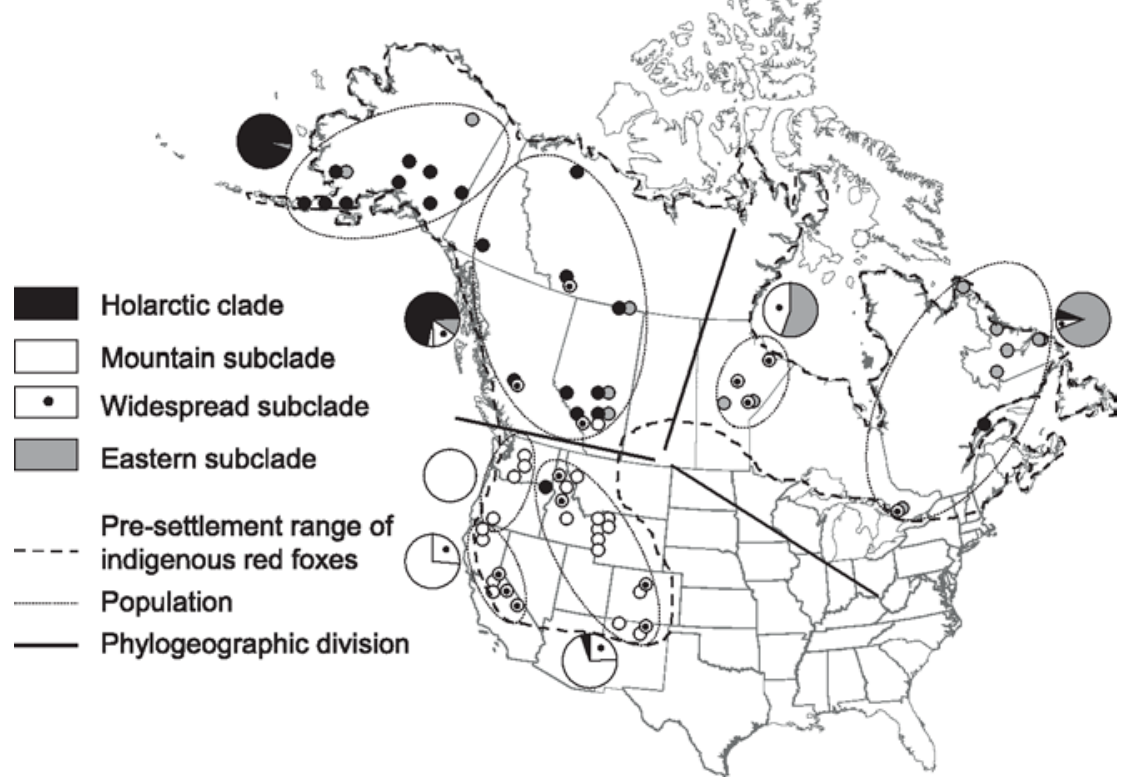

Fig. 5 Geographic distribution of cytochrome $b$ (a) and D-loop (b) mtDNA haplotypes among indigenous populations of the North American red fox. Specimens are shaded according to their clade, and pie charts indicate the proportional representation of clades in each geographical area. Thick lines partition the populations into groups as indicated by sAMovA. Shading of clades in Fig. 5(a,b) corresponds to shading used in the phylograms presented in Figs 2 and 3, respectively. 

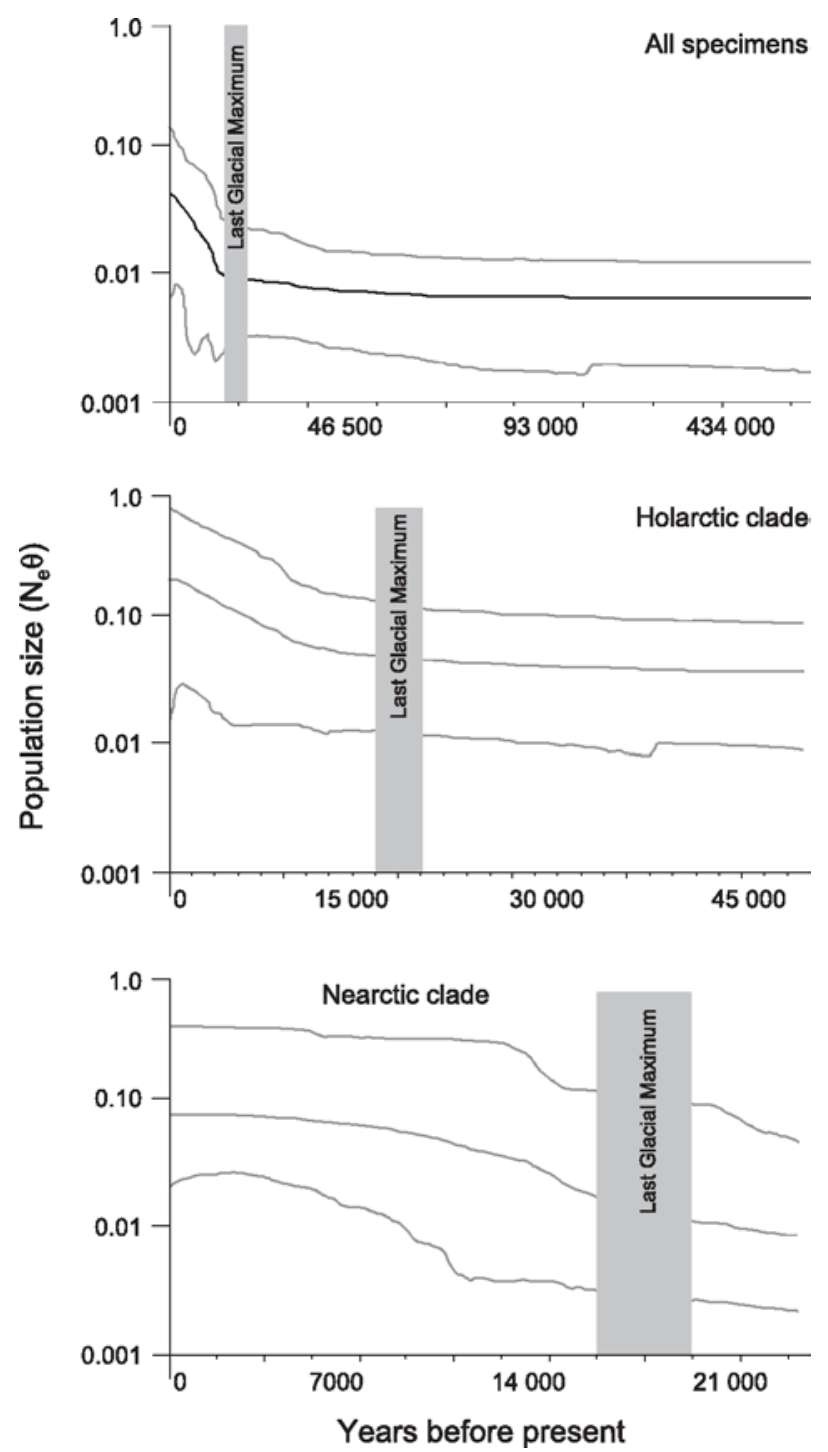

Fig. 6 Demographic fluctuations based on Bayesian skyline plots derived from 354 bp of the cytochrome $b$ gene for North American red foxes; all specimens; Holarctic clade only; and Nearctic clade only. The $x$ axis represents time in the past calculated in units of mutations per site; we estimated a mutation rate of 0.001 mutations per site each 35754 years. The $x$ axes vary in scale because each data set represents a different set or subset of lineages that coalesced at various times in the past. The $y$ axis depicts the population size as $N_{e} \theta$. The black line is the median population size estimate, and the shaded lines represent the upper and lower 95\% highest 
posterior density intervals. For reference, we have highlighted the coldest period around the Last Glacial Maximum (20 000 years ago). 